\title{
Article \\ Synthesis of Nano-ZnO/Diatomite Composite and Research on Photoelectric Application
}

\author{
Beibei Yang ${ }^{1}$, Xuefei Liu ${ }^{1}$, Zixu Ma ${ }^{1}$, Qian Wang ${ }^{2}$ and Junjiao Yang ${ }^{1,2, *}$ \\ 1 College of Chemsity, Beijing University of Chemical Technology, Beijing 100029, China; \\ yangbeibei8896@163.com (B.Y.); liuxf0116@163.com (X.L.); 2019210576@mail.buct.edu.cn (Z.M.) \\ 2 Analysis and Test Center of Beijing University of Chemical Technology, \\ Beijing University of Chemical Technology, Beijing 100029, China; wqian@mail.buct.edu.cn \\ * Correspondence: yangij@mail.buct.edu.cn
}

check for

updates

Citation: Yang, B.; Liu, X.; Ma, Z.; Wang, Q.; Yang, J. Synthesis of Nano-ZnO/Diatomite Composite and Research on Photoelectric

Application. Catalysts 2021, 11, 1232. https://doi.org/10.3390/catal11101232

Academic Editors: Wonyong Choi, Detlef W. Bahnemann,

Ioannis Konstantinou, Ewa Kowalska, Magdalena Janus, Vincenzo Vaiano and Zhi Jiang

Received: 6 September 2021

Accepted: 11 October 2021

Published: 13 October 2021

Publisher's Note: MDPI stays neutral with regard to jurisdictional claims in published maps and institutional affiliations.

Copyright: (c) 2021 by the authors. Licensee MDPI, Basel, Switzerland. This article is an open access article distributed under the terms and conditions of the Creative Commons Attribution (CC BY) license (https:/ / creativecommons.org/licenses/by/ $4.0 /)$.
Abstract: The key to the commercialization of sustainable energy conversion technologies is the development of high-performance catalysts. The discovery of a stable, efficient, and low-cost multifunction catalysts is the key. We used a simple green precipitation method to load nanozinc oxide particles onto a diatomite substrate. The $\mathrm{ZnO}$ is nano-sized. This precipitation method produces $\mathrm{ZnO}$ nanoparticles in situ on diatomite. The catalysts degraded $90 \%$ of Methylene blue solution and also degraded gaseous benzene and gaseous acetone. Not only can the catalysts be used for the organic degradation of wastewater, but it also has the potential to degrade volatile organic compounds. Photocatalytic efficiency is closely related to the generation and separation of photogenerated electrons and holes. The effective suppression of the recombination rate of photoliving carriers and thus improvement of the photocatalytic activity, has become a key research area. At present, photocatalysis is an effective technology to inhibit photogenerated carrier recombination, which is often studied in sewage treatment. Photoelectrochemical decomposition of water reduces the recombination of photogenerated electrons and holes by applying an external bias, thus improving the quantum efficiency for the complete mineralization of organic pollutants. The composite catalysts were used for oxygen and hydrogen extraction reactions, and a comparison of the catalysts with various loading ratios showed that the photoelectrochemical decomposition of water activity of the composite catalysts are due to pure $\mathrm{ZnO}$, and the efficiency is highest when the loading ratio is $10 \%$. This work provides new methods for the design and further optimization of the preparation of photoelectrochemical decomposition of water catalysts.

Keywords: photoelectric; $\mathrm{ZnO}$ nanoparticles; sewage treatment; volatile organic compounds; semiconductor; water splitting

\section{Introduction}

Photocatalytic technology is now considered the most promising technology for addressing energy shortages and environmental pollution. $\mathrm{TiO}_{2}$ and $\mathrm{ZnO}$ are important semiconductor materials that are widely used in fields such as solar cells [1,2], photocatalysis [3], and environmental restoration. However, the solar energy utilization of photocatalysts is low, and the stability of photogenerated electrons and holes is poor [4]. $\mathrm{ZnO}$ is a common semiconductor material with a band gap width of approximately $3.1 \sim 3.2 \mathrm{eV}$, with visible light response properties and appropriate valence band and conduction band positions, possessing strong oxidation-reduction capability. Extensive studies have shown that $\mathrm{ZnO}$ has good photocatalytic activity for organic pollutant degradation under visible light [5]. Although $\mathrm{ZnO}$ has a suitable band gap, nano $\mathrm{ZnO}$ particles in powder state are small, and industrial use will cause harm to the human respiratory tract; nevertheless, it is an effective way to load nano $\mathrm{ZnO}$ to a larger substrate material from the perspective of increased use [6]. In addition, in terms of increasing the photocatalytic efficiency, $\mathrm{ZnO}$ can be modified with alterations, including appearance regulation [7], elements doping [8], 
crystal surface regulation [9], and the construction of heterojunctions [10-12]. It was shown that an oxygen vacancy, such as a crystal defect, can introduce new Fermi levels into photocatalysts, increase the density of the photogenerated carriers, promote the separation of the photogenerated carriers, broaden the range of the visible light response, and significantly improve the performance of the photocatalysts [13].

In this study, $\mathrm{ZnO}$ composites with various loading ratios were synthesized by a precipitation method using diatomite as the carrier. Diatomite has the advantages of large specific surface area, many pores and a large number of hydroxyl groups on the surface $[14,15]$. Photocatalytic materials were analyzed by X-ray diffraction (XRD), scanning electron microscopy (SEM), and high-resolution transmission electron microscopy (HRTEM). Methylene blue (MB) was chosen as the target pollutant to investigate the effect of oxygen vacancy concentration on the degradation performance of the photocatalysts $[16,17]$.

\section{Results and Discussion}

\subsection{Phase Analysis}

Figure 1 shows the XRD patterns of pure diatomite, pure $\mathrm{ZnO}$, and $\mathrm{X} \% \mathrm{ZnO} @$ diatomite. The diffraction peaks at $31.8^{\circ}, 34.4^{\circ}, 36.2^{\circ}, 47.5^{\circ}, 56.6^{\circ}, 62.8^{\circ}$, and $67.9^{\circ}$ correspond to the crystal faces (100), (002), (101), (102), (110), (103), and (112) of hexagonal wurtzite ZnO, respectively $[18,19]$. The peaks at $21.8^{\circ}$ and $36.5^{\circ}$ are attributed to the $\mathrm{SiO}_{2}$ features in diatomite. All of the catalysts with various loading ratios show the coexistence of an anatase phase with no additional peak, implying that no impurities appear when $\mathrm{ZnO}$ is supported on diatomite. The reflection peak of diatomite becomes relatively low compared with that of $\mathrm{ZnO}$, and the pure diatomite peak is not too weak in the X\%ZnO@diatomite. Therefore, the introduction of diatomite does not affect the crystal structure of the catalysts. This result is consistent with the SEM and HRTEM characterizations.

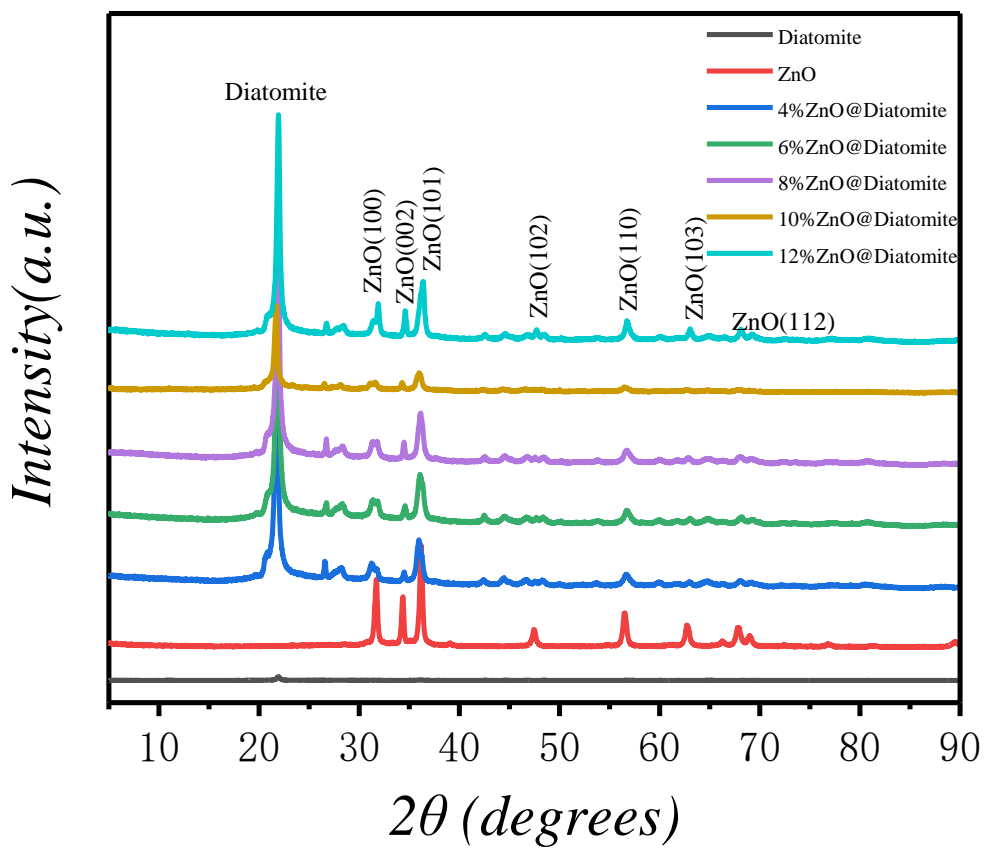

Figure 1. XRD patterns of pure diatomite, pure $\mathrm{ZnO}$, and $\mathrm{X} \% \mathrm{ZnO} @$ diatomite.

\subsection{SEM and HRTEM Investigations}

The appearance of the catalysts were characterized by SEM and HRTEM, as shown in Figure 2. It can be seen in Figure 2(A1,A2) that pure diatomite without the loading of $\mathrm{ZnO}$ nanoparticles has the appearance of a sunflower, with a smooth surface and numerous pores. The SEM images of pure $\mathrm{ZnO}$ displayed in Figure 2(B1,B2) indicate that the $\mathrm{ZnO}$ nanoparticles are prism-like, and the diameter of the pure $\mathrm{ZnO}$ particles measure 
approximately $45 \mathrm{~nm}$ in size, corresponding to the results of UV diffuse calculations. As is shown in the SEM images, $\mathrm{ZnO}$ with molar ratio loads of $10 \%$ Figure $2(\mathrm{C} 1, \mathrm{C} 2)$, the size of $\mathrm{ZnO}$ with a loading molar ratio of $10 \%$ on diatomite is about $15-20 \mathrm{~nm}$. As shown in the HRTEM image in Figure 2(D1,D2), the lattice distance of $\mathrm{ZnO}$ is approximately $0.2488 \mathrm{~nm}$, corresponding to the (101) plane of anatase $\mathrm{ZnO}$.

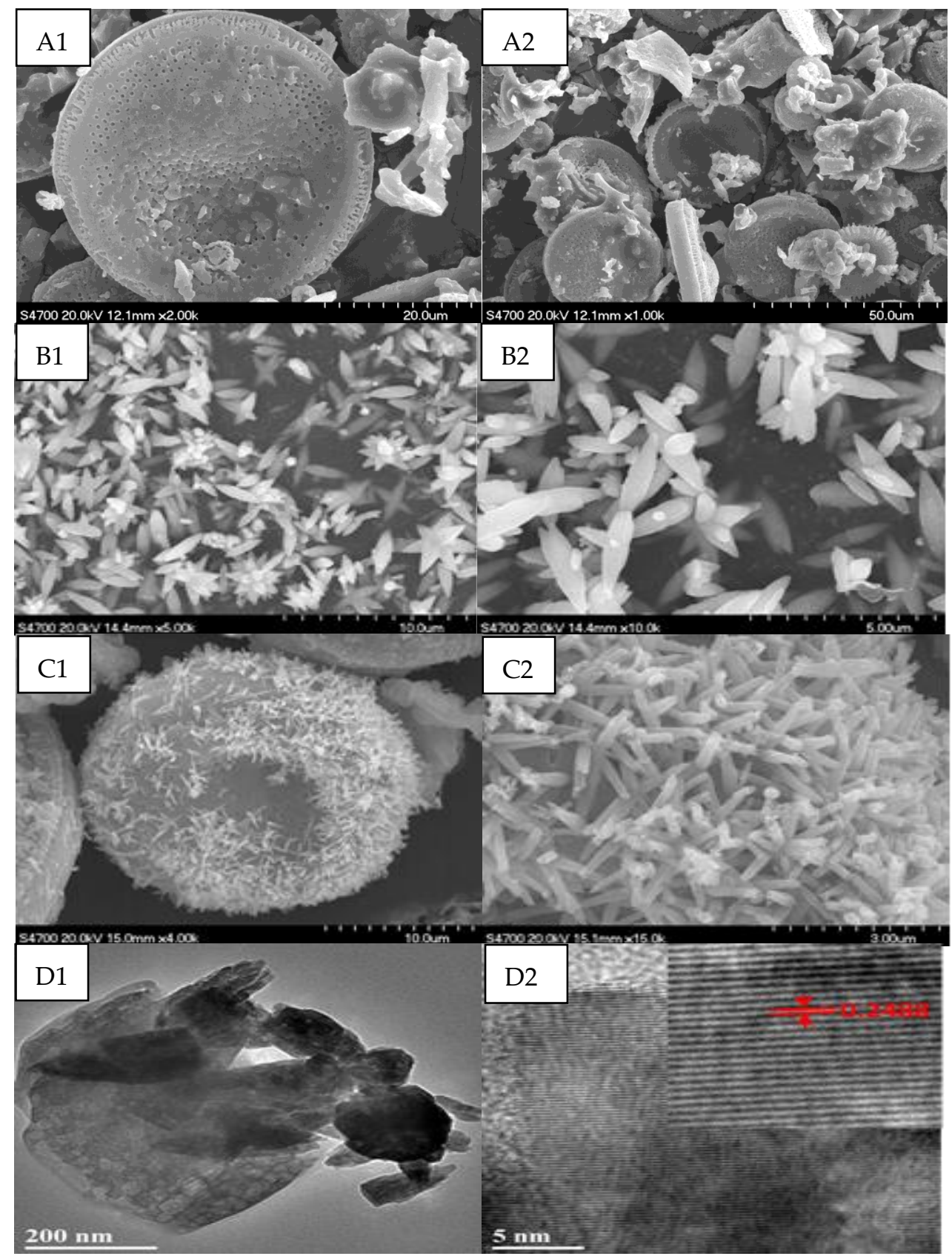

Figure 2. SEM images with different magnifications of (A1,A2) diatomite, (B1,B2) ZnO, and (C1,C2) 10\% ZnO@diatomite; (D1,D2) HRTEM images of 10\% ZnO@diatomite.

\subsection{EDS Analysis}

Figure 3 shows the diagram of the energy dispersive spectroscopy (EDS) and elemental mapping of the 10\% ZnO@diatomite sample, which clearly shows that $\mathrm{ZnO}$ nanoparticles are uniformly distributed on the diatomite surface of silicon, and the $\mathrm{Zn}, \mathrm{O}$, and Si elements are evenly distributed. 

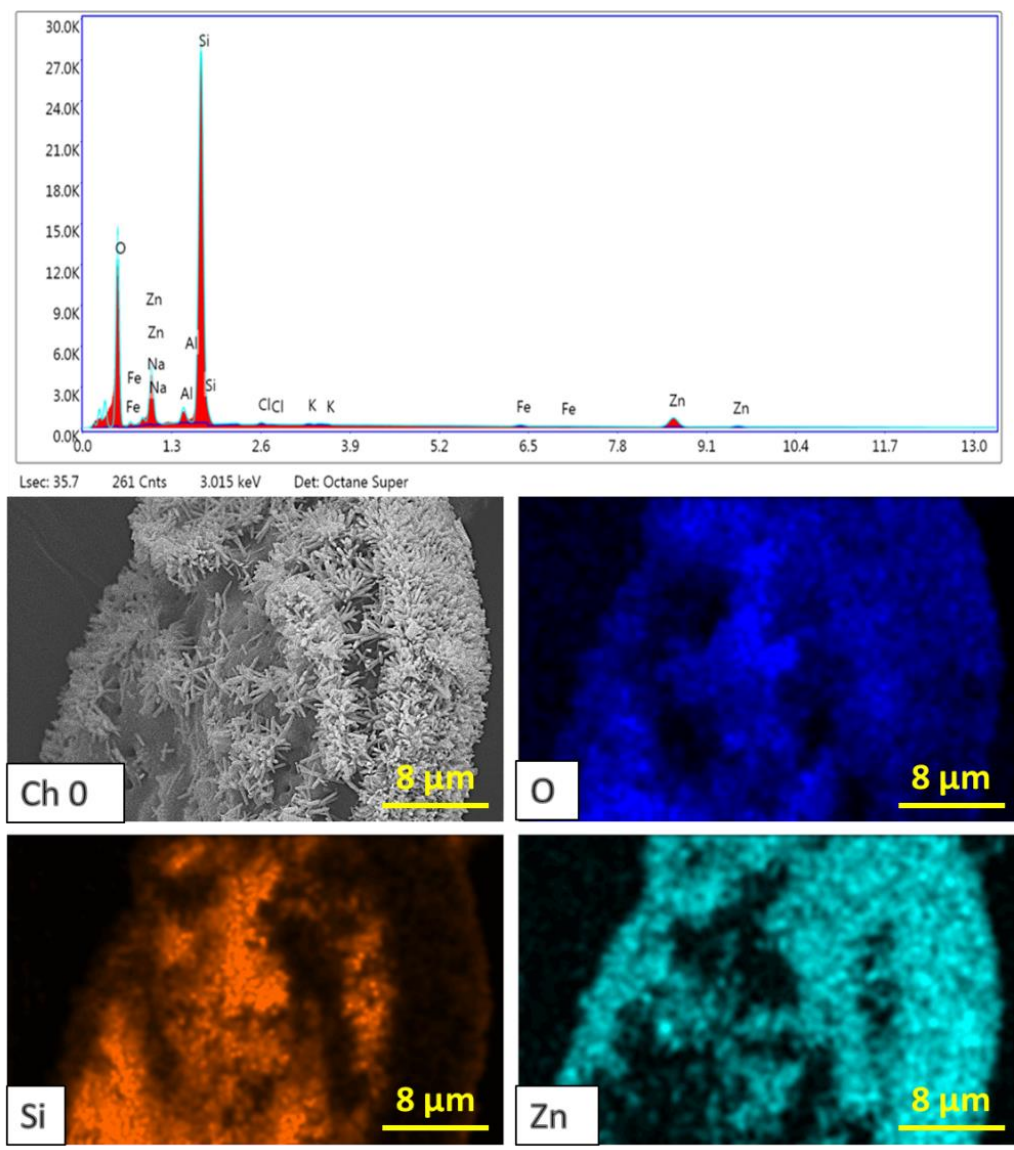

Figure 3. EDS and corresponding elemental mapping of 10\% ZnO@diatomite.

\subsection{EPR Analysis}

For the photodegradation of organic dyes, three main active substances participate in the reaction, i.e., photoliving holes $\left(\mathrm{h}^{+}\right)$, hydroxyl radicals $(\cdot \mathrm{OH})$, and hyperoxygen radicals $\left(\cdot \mathrm{O}_{2}^{-}\right)[20,21]$. In order to explore the mechanisms of this photocatalytic process, triethanolamine (TEOA), isopropanol (IPA), and ascorbic acid (VC) were used to capture $\mathrm{h}^{+}, \mathrm{OH}$, and $\mathrm{O}_{2}{ }^{-}$active species with capture amounts of $1 \mathrm{mmol}$, and the results are shown in Figure $4 \mathrm{~h}$. Figure $4 \mathrm{~h}$ shows that the degradation rate of MB solution without any free radical scavengers was $88.28 \%$ under visible light, while the degradation rate of the experimental group with the free radical scavengers decreased to different degrees, with TEOA at $83.73 \%$, IPA at $34.96 \%$, and VC at $39.71 \%$, respectively. This result shows that the influence of active species on photocatalytic MB solution is in the order of $\mathrm{h}^{+}<\cdot \mathrm{O}_{2}^{-}<\cdot \mathrm{OH}$. The photocatalytic properties of the material are closely related to the number of active species produced in the reaction system, so the electron paramagnetic resonance(EPR) technique was used to characterize the active species $\mathrm{h}^{+}, \cdot \mathrm{OH}$, and $\cdot \mathrm{O}_{2}^{-}$. Figure $4 \mathrm{a}-\mathrm{g}$ shows the signals of active species $\mathrm{h}^{+}, \cdot \mathrm{OH}$, and $\cdot \mathrm{O}_{2}^{-}$. After irradiation with the xenon lamp, all active species can be detected, and the signal intensity of the active species increases with the increase of xenon lamp irradiation time. In Figure $4 a-c$, the samples were irradiated with the xenon lamp for $4 \mathrm{~min}$ or $8 \mathrm{~min}$, and pure $\mathrm{ZnO}$ nanoparticles had the strongest signal of $\cdot \mathrm{OH}$. In Figure $4 \mathrm{~d}-\mathrm{f}$, the samples were irradiated with the xenon lamp for $4 \mathrm{~min}$ or $8 \mathrm{~min}$, and $10 \% \mathrm{ZnO@diatomite} \mathrm{had} \mathrm{the} \mathrm{strongest} \mathrm{signal} \mathrm{of} \cdot \mathrm{O}_{2}^{-}$. In Figure $4 \mathrm{~g}$, the oxygen vacancy defect test results showed the largest number of oxygen vacancy defects in $10 \%$ $\mathrm{ZnO@diatomite,} \mathrm{indicating} \mathrm{that} \mathrm{the} \mathrm{ability} \mathrm{of} \mathrm{the} \mathrm{photocatalytic} \mathrm{degradation} \mathrm{of} \mathrm{the} \mathrm{MB}$ solution is more closely related to $\cdot \mathrm{O}_{2}^{-}$and oxygen vacancies. 
(a)

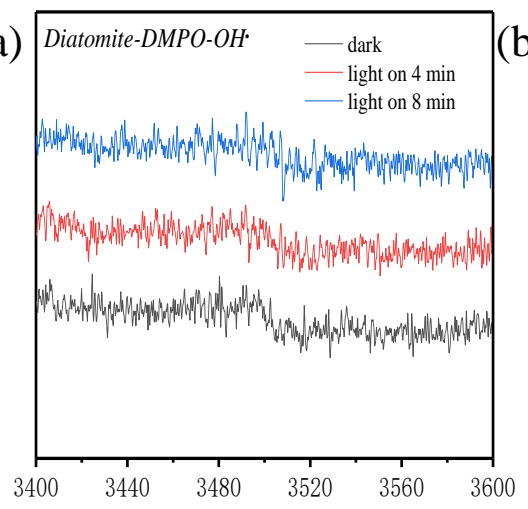

(d)
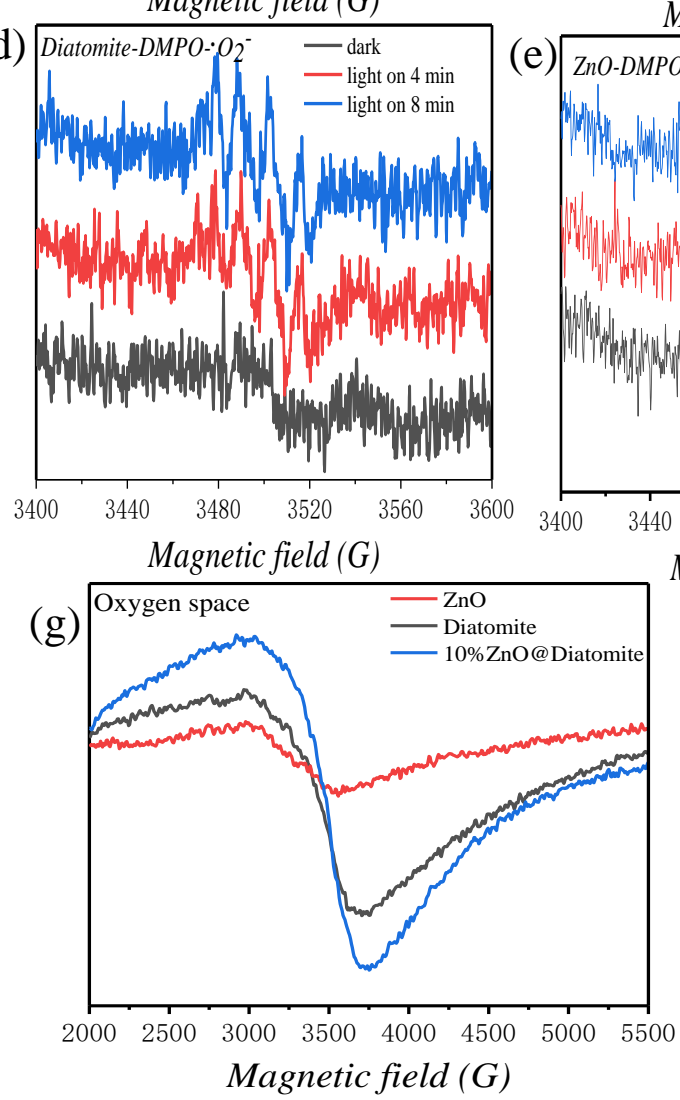
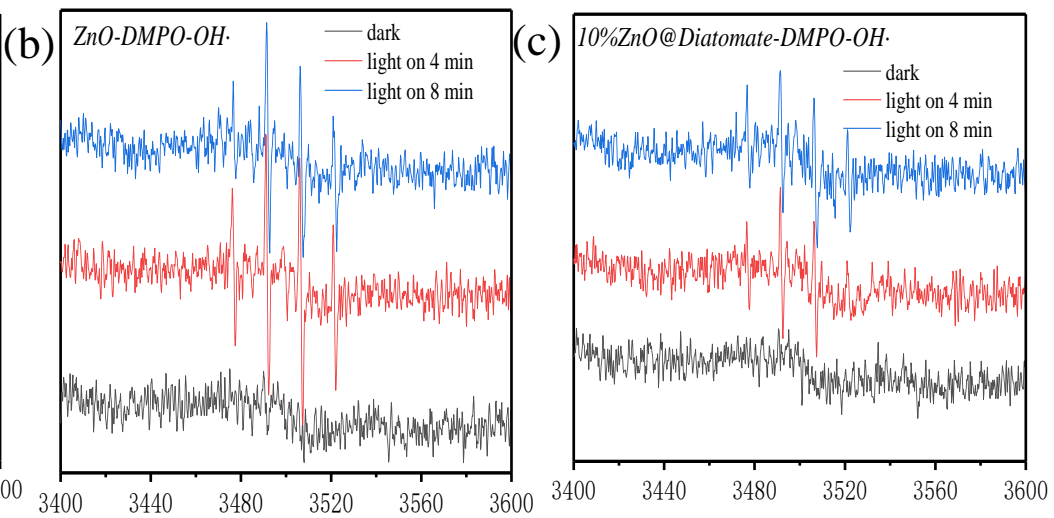

Magnetic field $(G)$

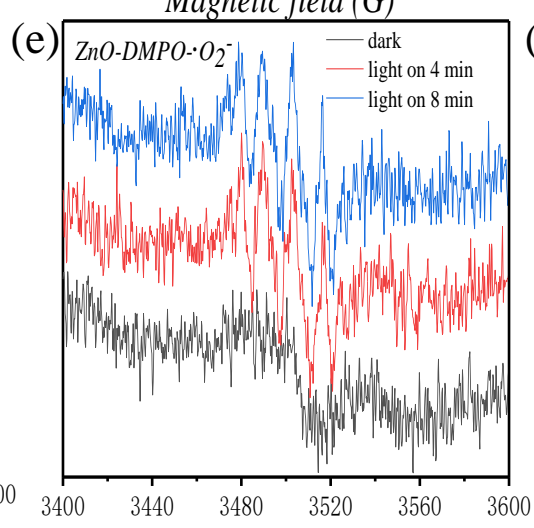

Magnetic field $(G)$

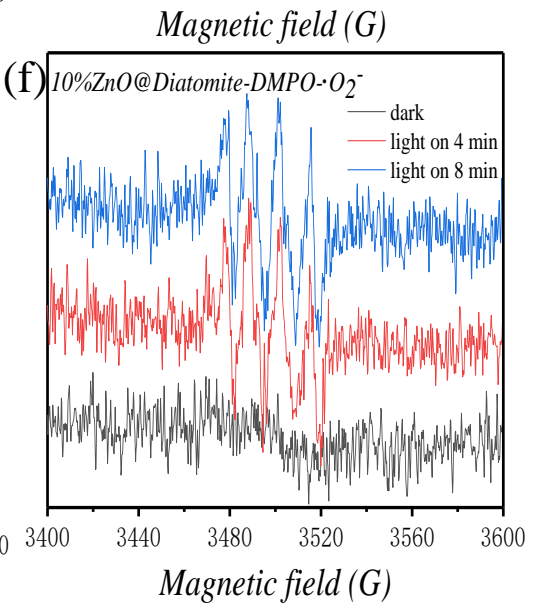

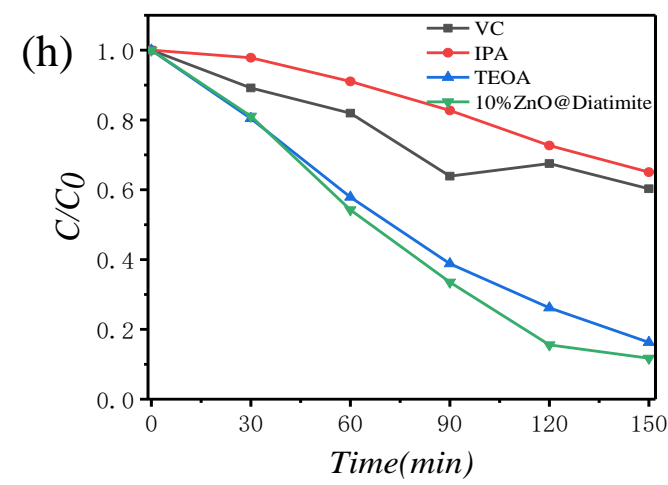

Figure 4. EPR spectra of the samples: (a) $\cdot \mathrm{OH}$ in diatomite; (b) $\cdot \mathrm{OH}$ in pure $\mathrm{ZnO}$; (c) $\cdot \mathrm{OH}$ in $10 \% \mathrm{ZnO} @$ diatomite; (d) $\mathrm{O}^{-2}$ in diatomite; (e) $\cdot \mathrm{O}^{-2}$ in pure $\mathrm{ZnO} ;(\mathbf{f}) \cdot \mathrm{O}^{-2}$ in $10 \% \mathrm{ZnO@diatomite;} \mathrm{(g)} \mathrm{oxygen} \mathrm{vacancy;} \mathrm{(h)} \mathrm{degradation} \mathrm{rate} \mathrm{of} \mathrm{MB}$ solution by $10 \% \mathrm{ZnO@diatomite} \mathrm{with} \mathrm{the} \mathrm{addition} \mathrm{of} \mathrm{free} \mathrm{radical} \mathrm{scavengers.}$

\subsection{XPS Analysis}

X-ray photoelectron spectroscopy (XPS) was conducted to analyze the elemental chemical environment $[22,23]$. Figure 5 shows the XPS results for pure $\mathrm{ZnO}$ and the composite catalyst with the loading ratio of $10 \%$. The survey spectra of the two catalysts are shown in Figure 5a, where only the three elements $\mathrm{Zn}, \mathrm{O}$, and $\mathrm{C}$ are displayed for pure $\mathrm{ZnO}$, and the four elements $\mathrm{Si}, \mathrm{Zn}, \mathrm{O}$, and $\mathrm{C}$ are shown for the composite catalyst with a loading ratio of $10 \%$. Figure $5 \mathrm{~b}$ shows the $2 \mathrm{p}$ peak of $\mathrm{Si}(102.9 \mathrm{eV})$ for diatomite. The $\mathrm{Zn} 2 \mathrm{p}$ spectrum for pure $\mathrm{ZnO}$ (Figure $5 \mathrm{c}$ ) shows a pair of peaks, at $1021.9 \mathrm{eV}\left(2 \mathrm{p}_{3 / 2}\right)$ and $1044.8 \mathrm{eV}\left(2 \mathrm{p}_{1 / 2}\right)$. The $\mathrm{Zn} 2 \mathrm{p}$ spectrum of composite catalysts (Figure $5 \mathrm{c}$ ) shows a pair of peaks at $1022.2 \mathrm{eV}\left(2 \mathrm{p}_{3 / 2}\right)$ and $1044.8 \mathrm{eV}\left(2 \mathrm{p}_{1 / 2}\right)$. The results demonstrate that the $\mathrm{ZnO}$ interacts with the diatomite and generates a $\mathrm{Zn}-\mathrm{O}-\mathrm{Si}$ bond. Figure $5 \mathrm{~d}$ is the $\mathrm{O}_{1 \mathrm{~s}}$ for the two catalysts; generally, $\mathrm{O}_{1 \mathrm{~s}}$ is divided into surface adsorption oxygen, metal-oxygen bonds, 
and oxygen vacancies. $\mathrm{O}_{1}$ indicates metal-oxygen, $\mathrm{O}_{2}$ is surface oxygen, and $\mathrm{O}_{3}$ is oxygen vacancies. After comparative analysis, as shown in Table 1 , the results show that $\mathrm{O}_{1}$ and $\mathrm{O}_{2}$ decreased slightly, while $\mathrm{O}_{3}$ increased significantly. The presence of oxygen vacancies in the composite catalysts improve photocatalytic performance.

(a)
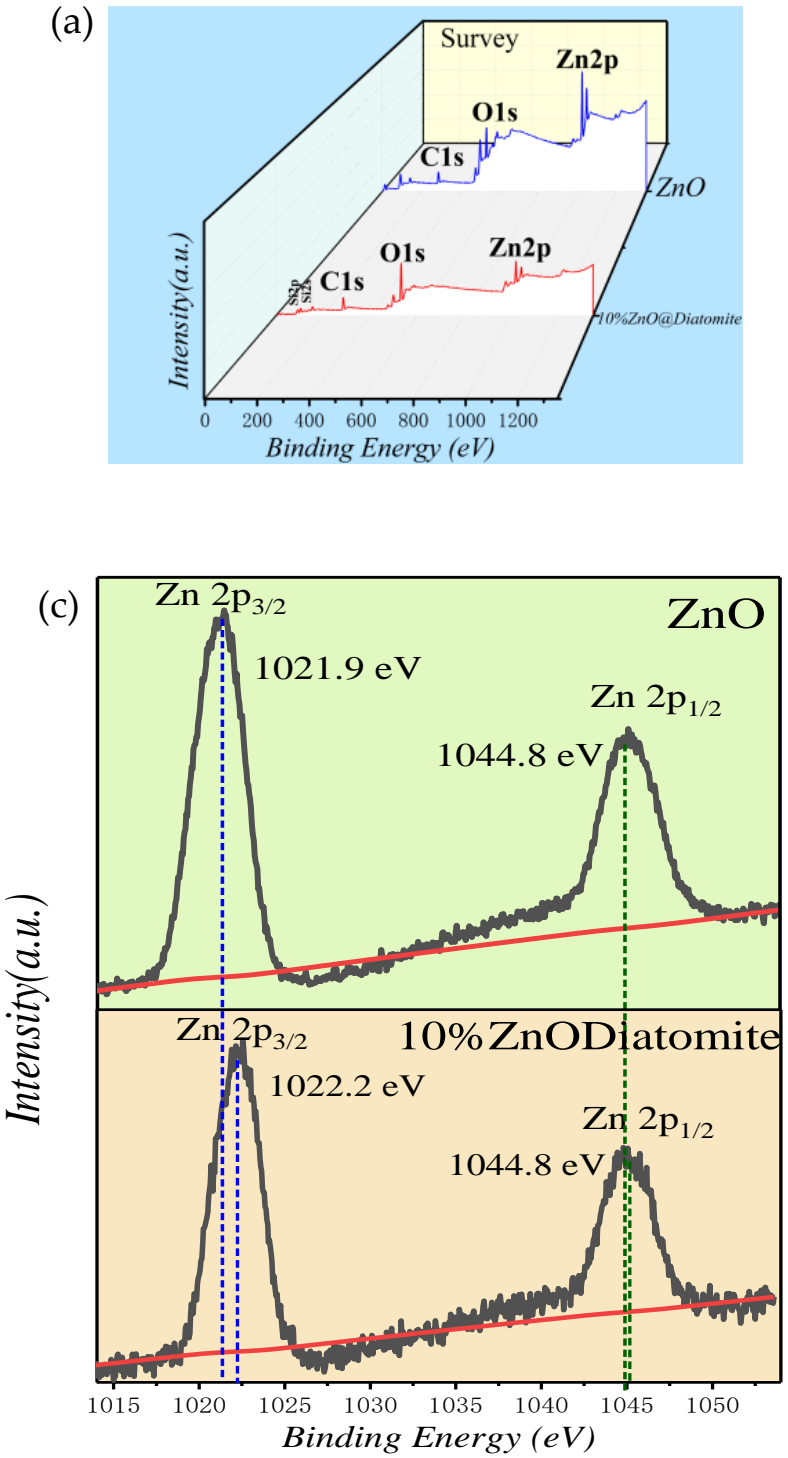

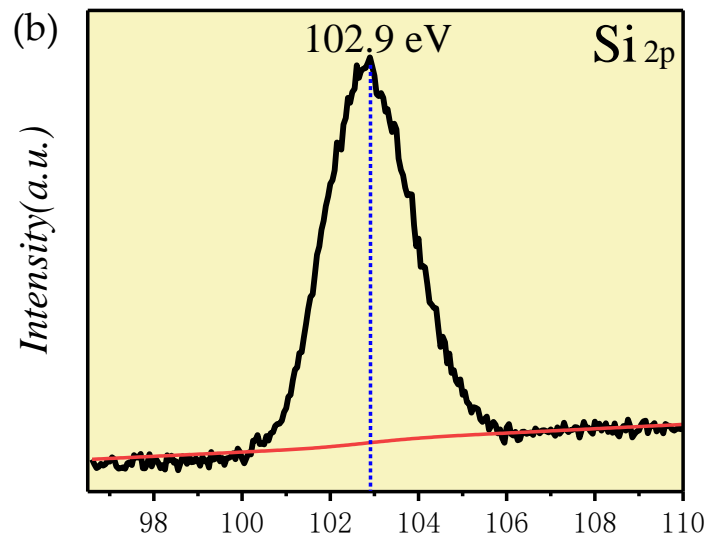

Binding energy $(\mathrm{eV})$

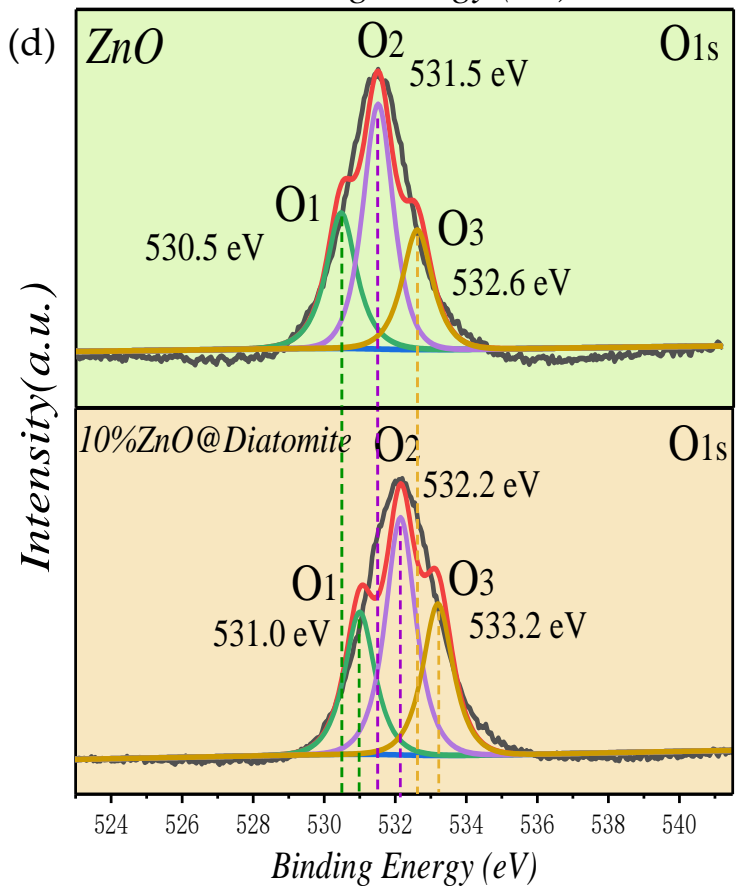

Figure 5. XPS survey spectra (a) and Si 2p (b), Zn 2p (c), and O 1s (d) spectra for ZnO and 10\% ZnO@diatomite.

Table 1. Ratio of three binding energy levels of $\mathrm{ZnO}$ and 10\% $\mathrm{ZnO} @$ diatomite.

\begin{tabular}{|c|c|c|c|}
\hline Sample $\quad$ Oxygen Species & $\mathrm{O}_{1}$ & $\mathrm{O}_{2}$ & $\mathrm{O}_{3}$ \\
\hline $\mathrm{ZnO}$ & $28.02 \%$ & $47.81 \%$ & $24.17 \%$ \\
\hline 10\%ZnO@diatomite & $26.77 \%$ & $44.67 \%$ & $28.56 \%$ \\
\hline
\end{tabular}

\subsection{BET Analysis}

As shown in Table 2, the specific surface areas of different catalysts were analyzed by Brunauer-Emmett-Teller (BET) test. The specific surface area of pure diatomite is small. Therefore, the contribution of diatomite to the specific surface area of the composites is very small. With the increase of loading rate, the specific surface area increases. The specific surface area of the composite catalyst with a loading rate of $10 \%$ is larger. These results show 
that the specific surface area is related to the photocatalytic performance. As can be seen from Figure 6, the diatomite shows International Union of Pure and Applied Chemistry (IUPAC) type-II isotherms, indicating the presence of micropores in the diatomite; the $\mathrm{X} \% \mathrm{ZnO@diatomite} \mathrm{composites} \mathrm{display} \mathrm{type-IV} \mathrm{isotherms} \mathrm{with} \mathrm{an} \mathrm{overlap} \mathrm{of} \mathrm{the} \mathrm{H} 2$ and $\mathrm{H} 3$ hysteresis loops, which is related to the deposition of $\mathrm{ZnO}$ nanoparticles on the surface of the diatomite.

Table 2. Surface and structural characterization of the catalysts.

\begin{tabular}{cc}
\hline Sample & BET Specific Surface Area $\left(\mathbf{m}^{2} / \mathbf{g}\right)$ \\
\hline Diatomite & 1.19 \\
$4 \%$ ZnO@diatomite & 1.38 \\
$6 \%$ ZnO@diatomite & 2.15 \\
$10 \%$ ZnO@diatomite & 2.52 \\
\hline
\end{tabular}

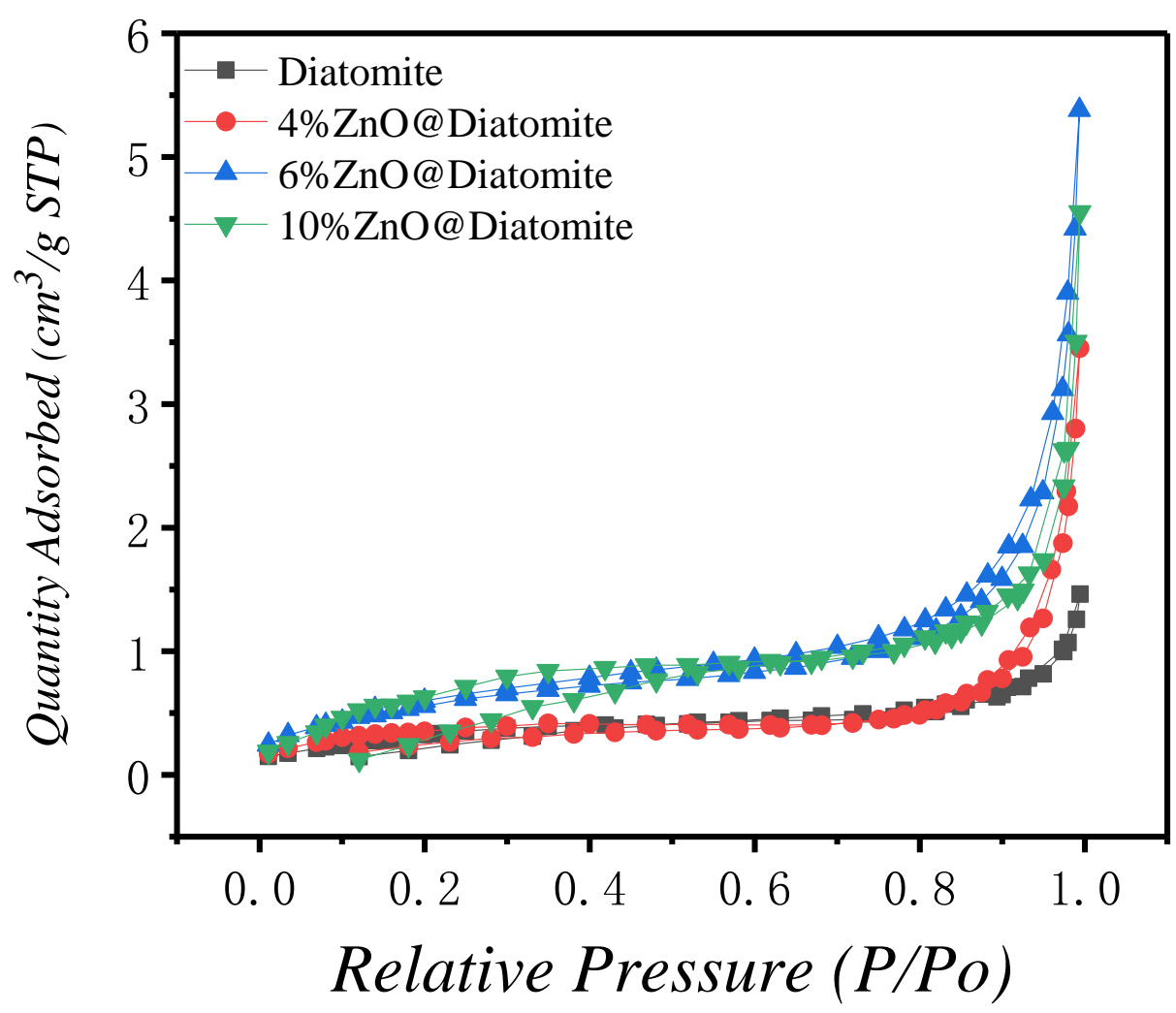

Figure 6. $\mathrm{N}_{2}$ adsorption-desorption isotherms of diatomite, and $\mathrm{X} \% \mathrm{ZnO@diatomite} \mathrm{composites.}$

\subsection{UV-Vis Diffuse Reflectance Spectra}

The absorption spectra of the samples were obtained by UV visible spectrophotometer (UV-vis) with a wavelength scanning range of $200 \sim 800 \mathrm{~nm}$, to characterize the light absorption characteristics of the catalysts [24]. From Figure 7a, nano $\mathrm{ZnO}$ has a distinct UV absorption peak at $376 \mathrm{~nm}$. However, for diatomite, there is no absorption about $400 \mathrm{~nm}$. For the catalysts with various molar loading ratios, there are obvious UV absorption peaks at $376 \mathrm{~nm}$, which proves the successful loading of $\mathrm{ZnO}$. The analytical data show that the composites with various molar loading ratios had strong ultraviolet absorption at $10 \%$. By using the Tauc plot, the band gaps of the samples were calculated. The broadening of the energy spacing of nanomaterials shows the size and the range of momentum and energy changes in electrons.

The light absorption coefficient satisfies the equation: $\alpha^{2}=(\mathrm{A} / \mathrm{h} v)(\mathrm{h} v-\mathrm{Eg}), \alpha$ is the light absorption coefficient, $\mathrm{A}$ is the proportional constant, $\mathrm{h}$ is the Planck constant, $v$ is the frequency of light, $\mathrm{h} v$ is the photon energy, Eg is the energy gap. The value of 
Eg is obtained by extending the linear part of the curve when $\alpha=0$. Figure $7 \mathrm{~b}$ shows the $(\alpha \mathrm{h} v)^{2}-(\mathrm{h} v)$ relationship curve of pure $\mathrm{ZnO}$ and 10\% $\mathrm{ZnO@diatomite,} \mathrm{from} \mathrm{which} \mathrm{the}$ band gap values are determined to be $3.26 \mathrm{eV}$ and $3.33 \mathrm{eV}$, respectively. Figure $7 \mathrm{c}, \mathrm{d}$ shows the XPS valence band spectra of pure $\mathrm{ZnO}$ and 10\% ZnO@diatomite, determining that the valence bands are located at $2.47 \mathrm{eV}$ and $3.09 \mathrm{eV}$, respectively. By combining the band gap values and valence values of the samples, the conduction bands bottom of pure $\mathrm{ZnO}$ and $10 \% \mathrm{ZnO} @$ diatomite are found at $-0.79 \mathrm{eV}$ and $-0.24 \mathrm{eV}$, respectively. It was reported in the literature that $\left(\mathrm{H}_{2} \mathrm{O} / \cdot \mathrm{OH}\right)$ has a redox potential of $2.38 \mathrm{eV}$, while the $\left(\mathrm{O}_{2} / \cdot \mathrm{O}_{2}^{-}\right)$redox potential is $-0.33 \mathrm{eV}$. Obviously, the calculated energy band structures for the samples conform to the formation of potential requirements for active species, such as $\cdot \mathrm{OH}$ and $\cdot \mathrm{O}_{2}^{-}$.

(a)

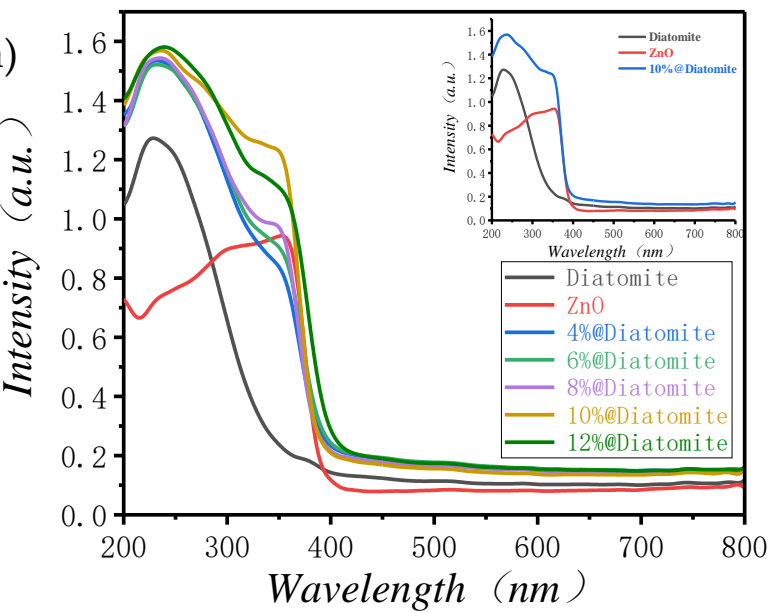

(c)

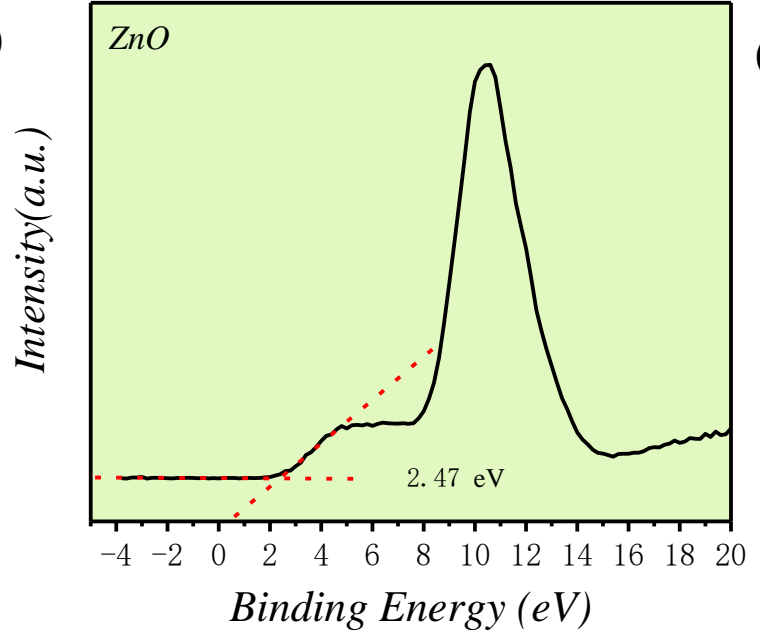

(b)

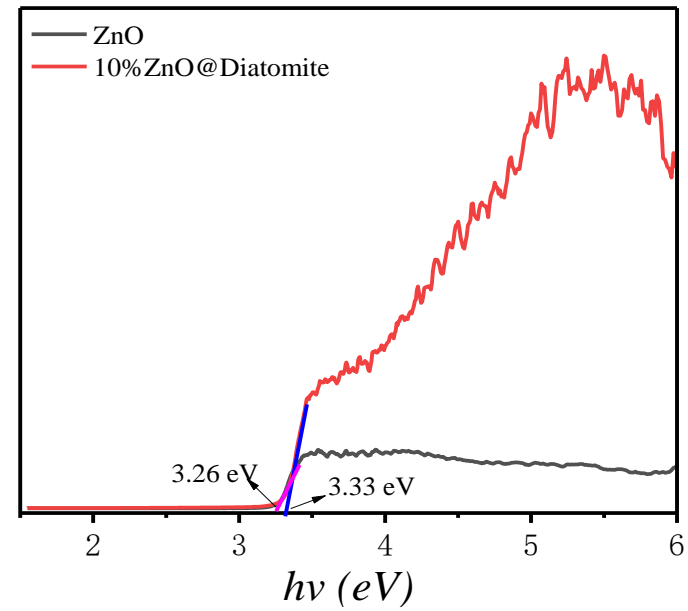

(d)

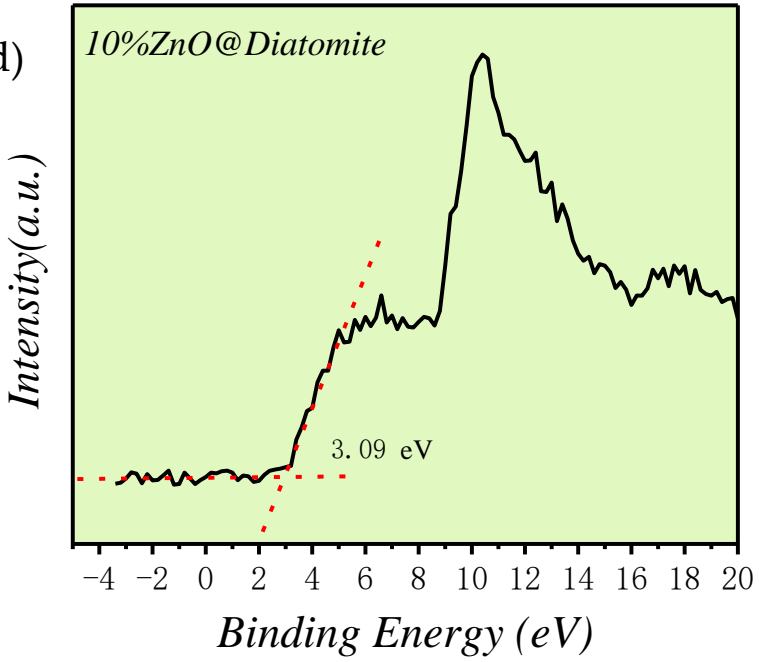

Figure 7. (a) UV-vis spectra of X\%ZnO@diatomite, (b) plots of $(\alpha \mathrm{h} v)^{2}$ versus $(\mathrm{h} v),(\mathrm{c}) \mathrm{XPS}$ valence band spectra of pure $\mathrm{ZnO}$, (d) XPS valence band spectra of $10 \% \mathrm{ZnO@diatomite.}$

\subsection{Photoluminescence (PL) Spectra}

The Photoluminescence (PL) spectra of the prepared samples are shown in Figure 8. Since most of the light absorption and excitation occur in the surface region of the photocatalyst, the emission mainly reflects the recombination of surface charges [25]. The recombination rate of electrons and holes is one of the important indexes to evaluate the photocatalytic performance of catalysts. With the decrease of recombination rate, the photocatalytic performance of catalysts increases [26,27]. The wavelength of the excitation light selected in the experiment was $300 \mathrm{~nm}$. The test results obtained are shown in Figure 8. The fluorescence intensity of zinc oxide loaded diatomite is lower than that of pure diatomite or zinc oxide. The composite with molar loading rate of $10 \%$ has the lowest fluorescence 
intensity and the best photocatalytic performance. The weakening in fluorescence intensity may be due to $\mathrm{ZnO}$ loading on diatomite; by forming $\mathrm{Si}-\mathrm{O}-\mathrm{Zn}$, $\mathrm{ZnO}$ nanoparticles can act as good electron captures and reduce the recombination of electrons and holes. Therefore, we concluded that the catalyst with the $\mathrm{ZnO}$ molar loading ratio of $10 \%$ was the most suitable for the photocatalytic degradation experiment.

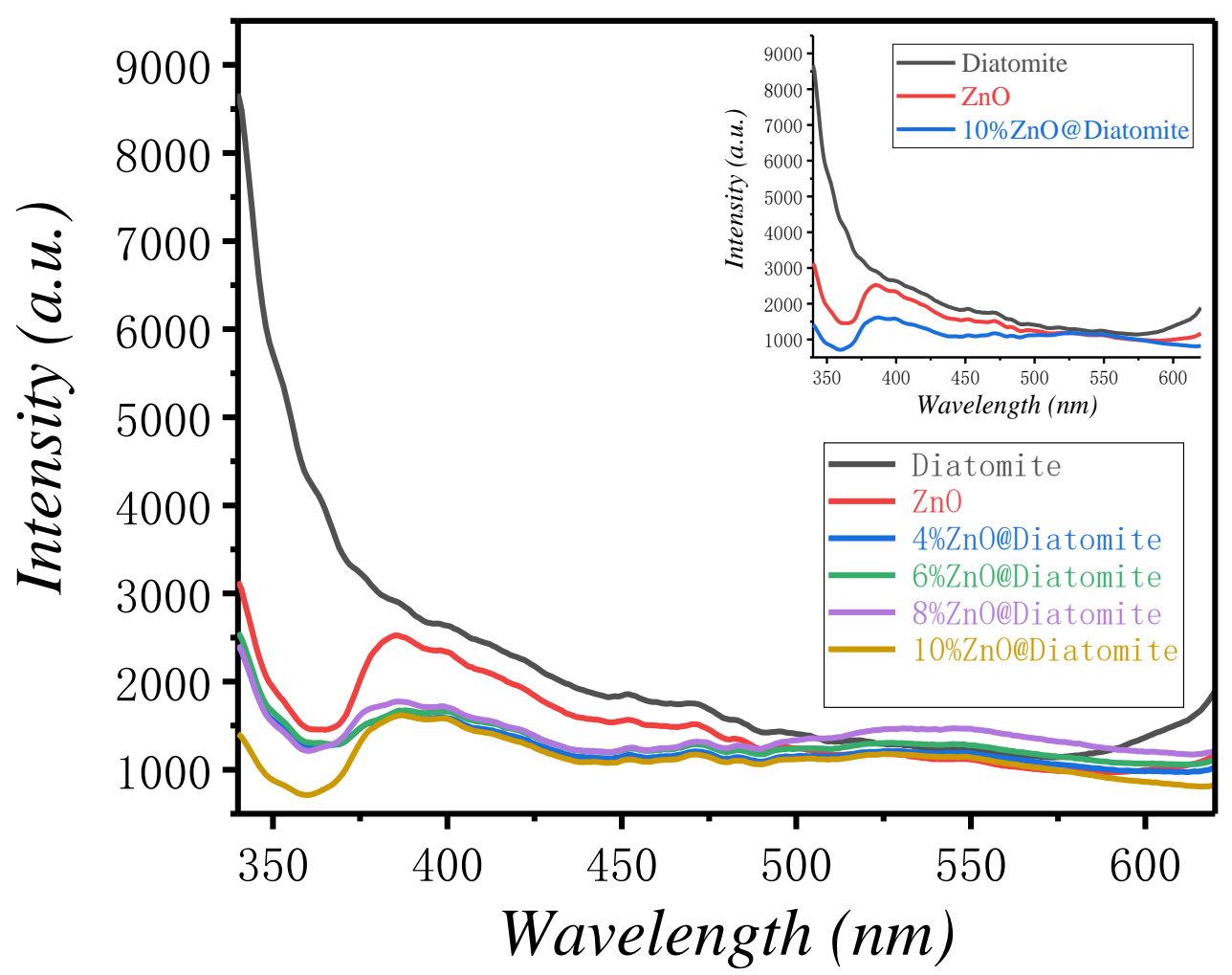

Figure 8. PL spectra of $\mathrm{ZnO}$, diatomite, and X\%ZnO@diatomite.

\subsection{Photocatalytic Performance of Catalysts}

Semiconductor photocatalytic technology is a catalytic oxidation technology that has received much research attention. Photocatalytic technology is a heterogeneous photocatalytic process under light irradiation, making it an ideal photocatalytic process to use sunlight as a light source and activate the oxidation-reduction reaction at room temperature [28-30]. Free radicals such as $\cdot \mathrm{OH}$ and $\cdot \mathrm{O}_{2}^{-}$generated during the reaction are highly oxidizing, so they can effectively break the chemical bonds in organic compounds, so as to realize the photocatalytic oxidation and decomposition of polluted wastewater, organic polluting substances, or harmful gases on the surface of objects. Scheme 1 illustrates the formation of $\mathrm{X} \% \mathrm{ZnO} @$ diatomite, and the reaction process of the photocatalytic oxidation of pollutants such as MB is shown in Figure 9. The reaction expression is as follows:

$$
\begin{gathered}
\mathrm{ZnO}+\mathrm{h} v \rightarrow \mathrm{h}^{+}+\mathrm{e}^{-} ; \\
\mathrm{H}_{2} \mathrm{O}+\mathrm{h}^{+} \rightarrow \cdot \mathrm{OH}+\mathrm{H}^{+} ; \\
\mathrm{O}_{2}+\mathrm{e}^{-} \rightarrow \cdot \mathrm{O}_{2}^{-} \\
\mathrm{OH}+\mathrm{MB} \rightarrow \mathrm{H}_{2} \mathrm{O}+\mathrm{CO}_{2} ; \\
\mathrm{O}_{2}^{-}+\mathrm{MB} \rightarrow \mathrm{H}_{2} \mathrm{O}+\mathrm{CO}_{2} ; \\
\mathrm{H}^{+}+\cdot \mathrm{O}_{2}^{-} \rightarrow \cdot \mathrm{OOH} \\
\cdot \mathrm{OOH}+\cdot \mathrm{OOH} \rightarrow \mathrm{O}_{2}+\mathrm{H}_{2} \mathrm{O}_{2} ; \\
\mathrm{H}_{2} \mathrm{O}_{2}+\mathrm{e}^{-} \rightarrow \mathrm{OH}^{-}+\cdot \mathrm{OH} ; \\
\cdot \mathrm{OH}, \cdot \mathrm{O}_{2}^{-} ; \mathrm{h}^{+}+\mathrm{MB} \rightarrow \mathrm{H}_{2} \mathrm{O}+\mathrm{CO}_{2}+\text { inorganic molecules. }
\end{gathered}
$$




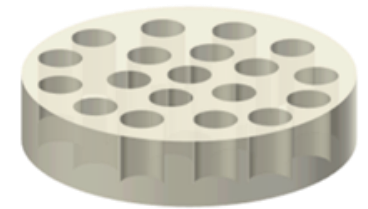

Diatomite

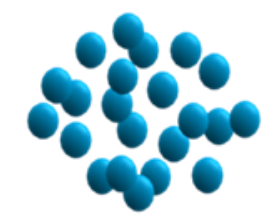

$\mathrm{ZnO}$ nanoparticles

Scheme 1. Schematic illustration of the formation of $\mathrm{ZnO@diatomite} \mathrm{composite} \mathrm{catalysts.}$

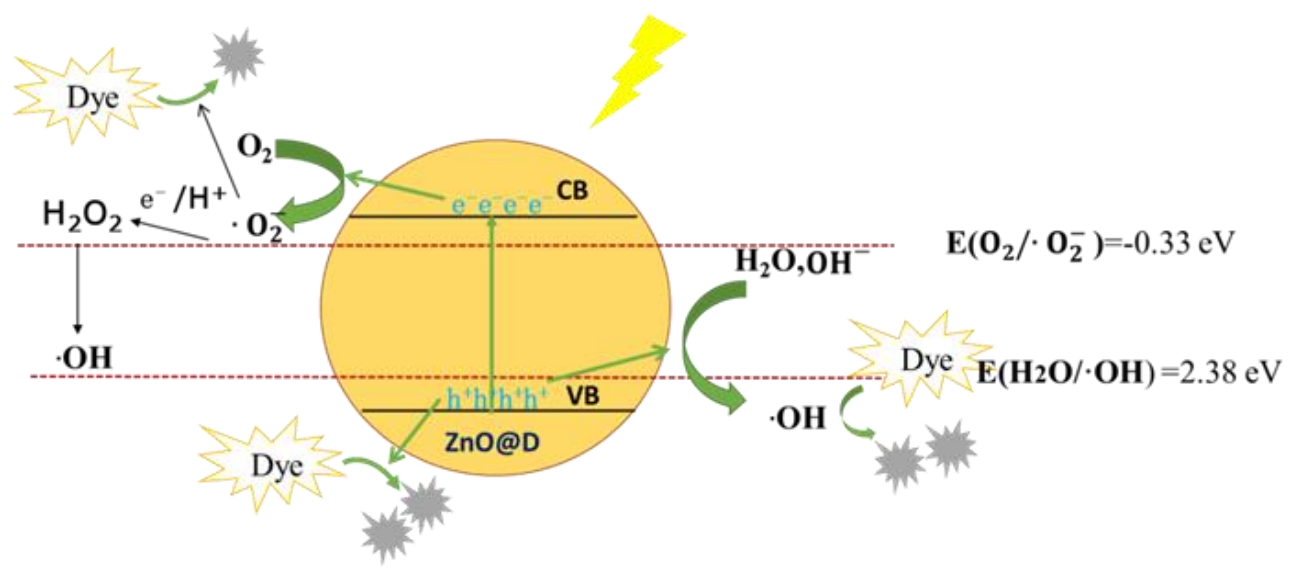

Figure 9. Schematic drawing of photocatalytic mechanism of $\mathrm{ZnO} @$ diatomite.

MB solution was used as the target degradator to evaluate the photocatalytic degradation ability of the catalysts with various molar loading ratios. By analyzing the specific surface area of the catalysts with various loading ratios, considering the strong adsorption capacity for MB solution under the condition of a low load, the optical absorption range was obtained by UV-vis spectroscopy, and the electron-hole recombination rate was determined by PL spectroscopy. The catalysts with a molar loading ratio of $10 \%$ had the best photocatalytic degradation efficiency, as shown in Figures 10 and 11. At the same degradation time, the catalyst degradation efficiency of the composite with a molar loading ratio of $10 \%$ reached $90 \%$, better than the catalysts with other loading ratios. The MB solution showed nearly no degradation with only diatomite. All the results are consistent with the UV-vis and fluorescence analysis conclusions. The optimal value of the load may be due to the aggregation of $\mathrm{ZnO}$ nanoparticles and the saturation of the number of $\mathrm{Si}-\mathrm{O}-\mathrm{Zn}$ bonds formed between diatomite and $\mathrm{ZnO}$, resulting in a lower degradation efficiency when the load was $12 \%$ compared with that when the loading ratio was $10 \%$.

Figure 12 shows the degradation results for gaseous acetone and gaseous benzene. The gas concentration was controlled by adding $1 \mathrm{~mL}$ of saturated gas at room temperature to headspace vials. As can be seen from Figure 12, under visible light irradiation, the optimal catalyst showed excellent photocatalytic performance for gaseous acetone and gaseous benzene at a certain concentration condition. As shown, both gaseous benzene and gaseous acetone degraded in various degrees after $180 \mathrm{~min}$ of light irradiation, with gaseous acetone having higher degradation efficiency than that of gaseous benzene, but both showed incomplete degradation in a short amount of time because the initial concentration was too high. One of the possible reasons for the analytical degradation results is that the structure of the gaseous benzene molecules is extremely stable and difficult to break. Another possible reason is that the concentration of gaseous benzene is too high or that it is a nonpolar molecule, and the degradation efficiency may be related to molecular polarity. In this study, only two gaseous organic pollutants were studied. In the future, we will study the catalytic degradation of other gaseous organic pollutants (such as methanol, ethanol 
and formaldehyde) and determine whether the effects on polar organic and non-polar organic properties are the same.

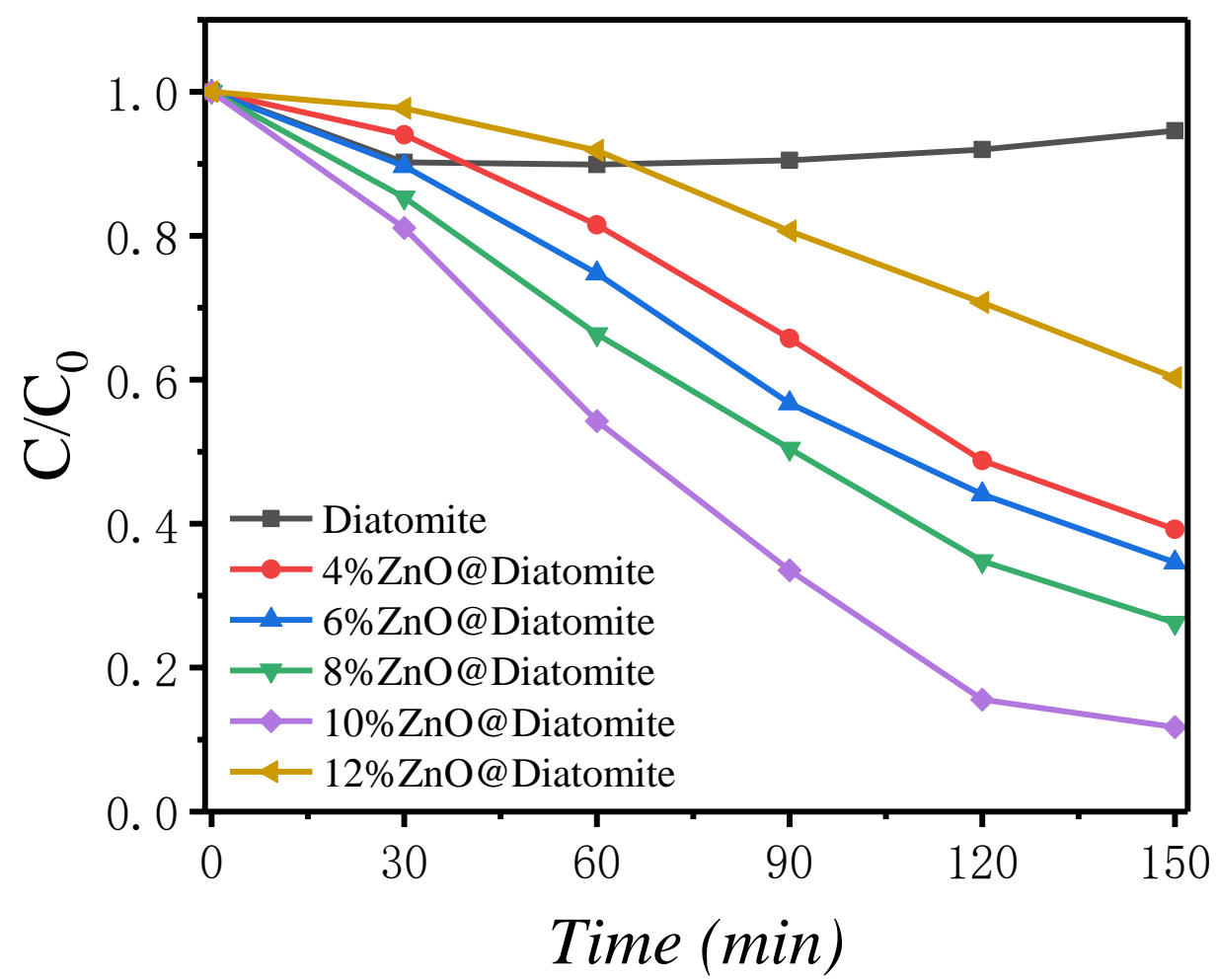

Figure 10. MB photodegradation over various catalysts under visible light.

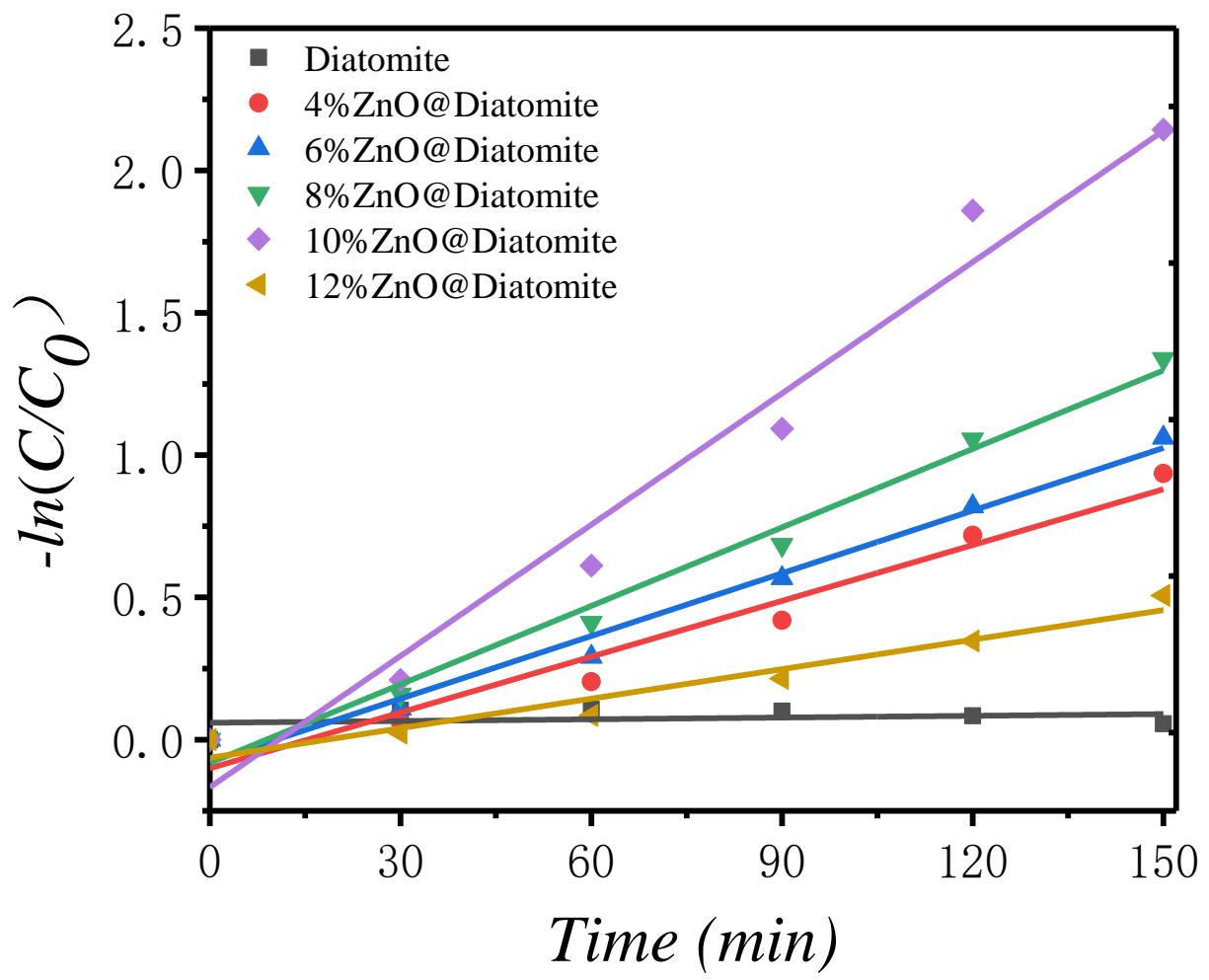

Figure 11. Primary kinetics fitting curve for photocatalytic degradation of MB. 


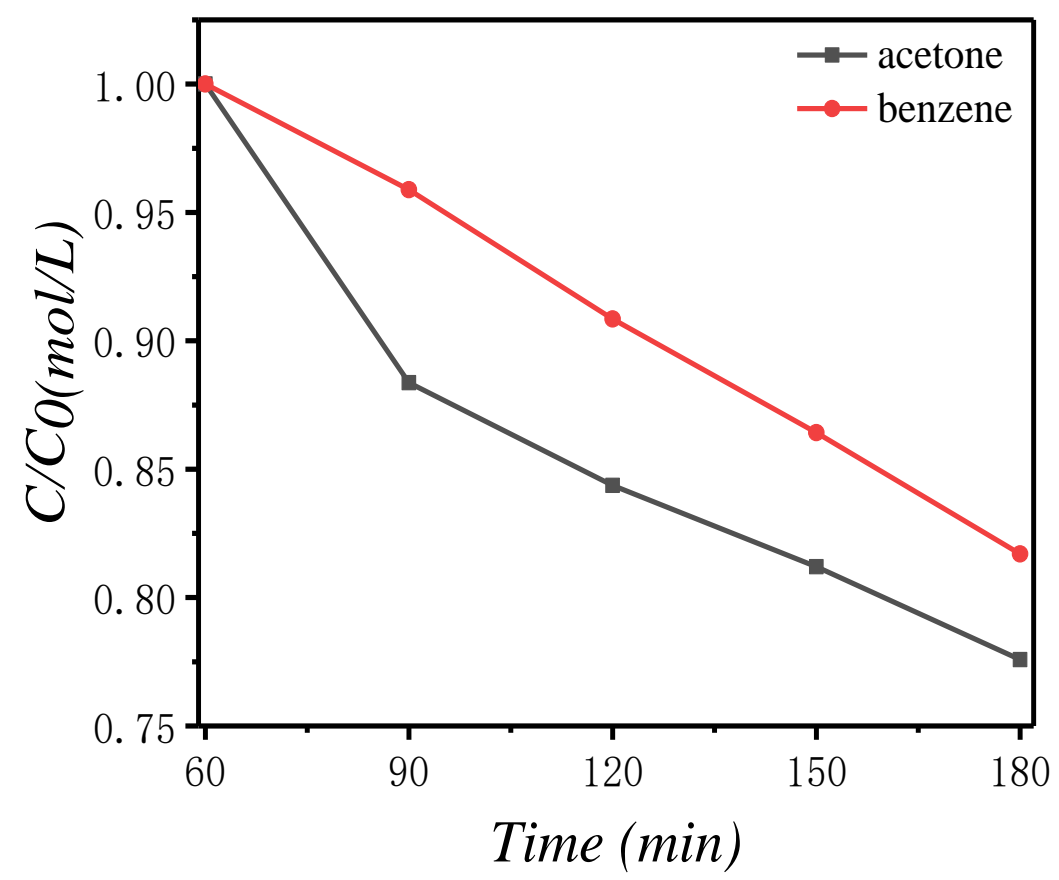

Figure 12. Photodegradation of certain concentrations of gaseous acetone and gaseous benzene over 10\% ZnO@diatomite under visible light irradiation.

\subsection{Photocurrent Analysis}

Figure 13a shows the Photocurrent-time dependences curve of pure $\mathrm{ZnO}$ and composite catalysts with various molar load ratios. The photocurrent density of $\mathrm{ZnO} @$ diatomite composite catalysts are higher than that of pure $\mathrm{ZnO}$, and the photocurrent density of catalyst with molar loading rate of $10 \%$ is the largest, indicating that the existence of oxygen vacancies can improve the separation efficiency of photogenerated electrons and holes, because the more oxygen vacancies, the greater the photocurrent density. The composites with various loading ratios were studied to determine the maximum photocurrent density, as shown in Figure 13b. The comparison between dark and light conditions reveals that the photocurrent density in light conditions is significantly greater than that in dark conditions. Among them, the maximum the photocurrent density of the composite with the loading ratio of $10 \%$ was $0.25 \mathrm{~mA} / \mathrm{cm}^{2}$ at $+0.8 \mathrm{~V}$ vs. Reversible Hydrogen Electrode (RHE). The composite has a high density, a high surface area, a high volume ratio, and a superior charge transport path, maximizing the photocurrent density. It is shown that 10\%ZnO@diatomite has the largest photocurrent among the composite catalysts because of its charge collection efficiency and direct path to photoelectrons.

In this study, the $\mathrm{ZnO} @$ diatomite composite catalysts generate $\mathrm{Zn}-\mathrm{O}-\mathrm{Si}$ bonds with similar heterogeneous structures, thus improving the Passivated Emitterand Rear Cell (PEC) performance. The ZnO@diatomite composite structure exhibits a higher absorbance in the UV-vis region compared with that of pure $\mathrm{ZnO}$ nanoparticles. Furthermore, the $\mathrm{ZnO}$ nanoparticles in the $\mathrm{ZnO} @$ diatomite composite catalysts have smaller diameters and length compared with pure $\mathrm{ZnO}$ nanoparticles, providing a higher surface-volume ratio for the electrode/electrolyte interface. Therefore, when the Fermi level changes because of the strong interface interaction, more electron-hole pairs are produced and separated effectively. Furthermore, $\mathrm{ZnO}$ nanoparticles with smaller particle sizes of the composite catalysts are more prone to adsorption and surface reaction, thus further promoting charge separation. Additionally, the recombination of the electorns and holes on the surface of $\mathrm{ZnO}$ nanoparticles were significantly reduced, as demonstrated by PL results. Therefore, compared with light absorption, the effective separation and transmission of photogenerated carriers are generally considered to be the main factors determining the performance of PEC [17].When loading rate of the $\mathrm{ZnO}$ is low, the electrolyte may directly meet the 
diatomite because of the small and uneven amounts of $\mathrm{ZnO}$, which hinders the separation of photogenerated charges with low photocurrent density. For the composite with a loading ratio of $10 \%$, the maximum photocurrent density is due to the optimal ratio, leading to the effective separation of the photogenerated carriers. When the load fraction is too high, $\mathrm{ZnO}$ nanoparticles can agglomerate, causing reduced photogenerated carriers separation. The optimal loading of nanoparticles is very important to improve the photocurrent density.

(a)

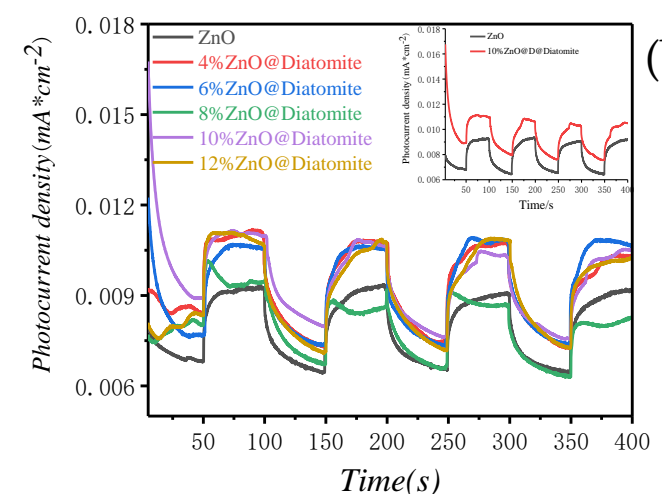

(c)

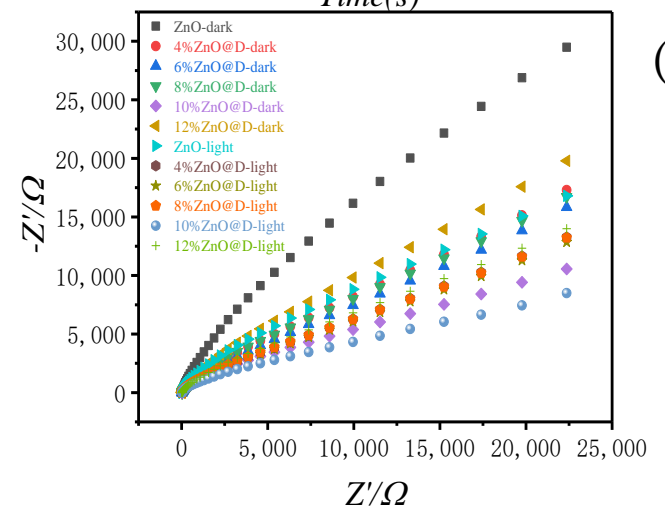

(e)

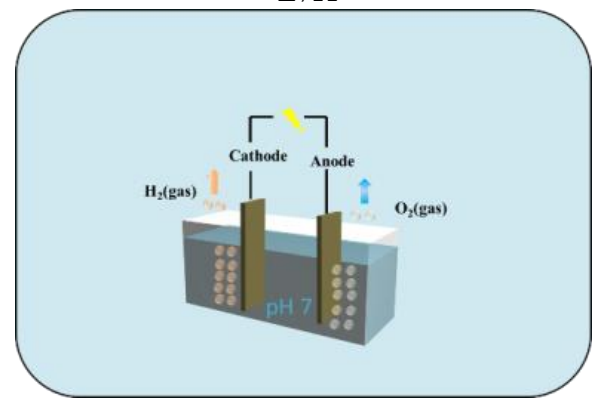

(b)

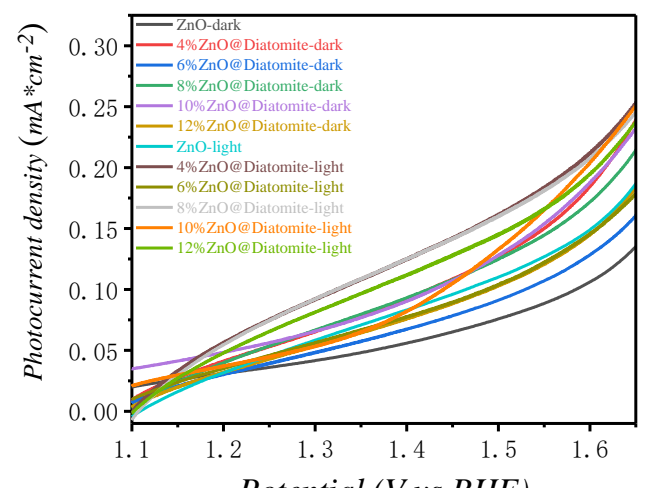

(d)

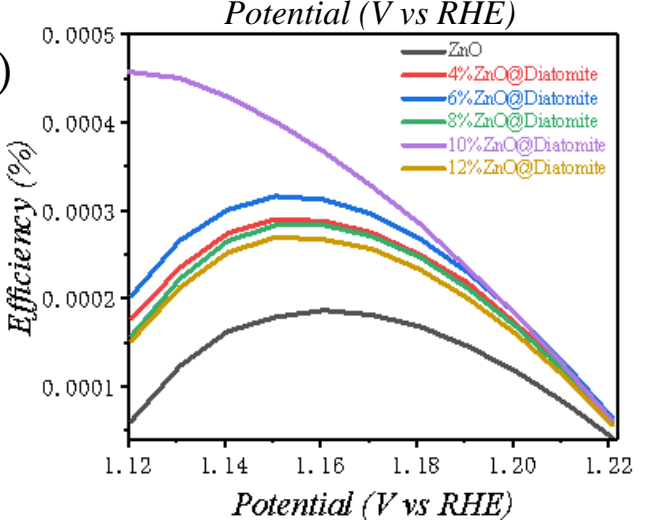

(f)

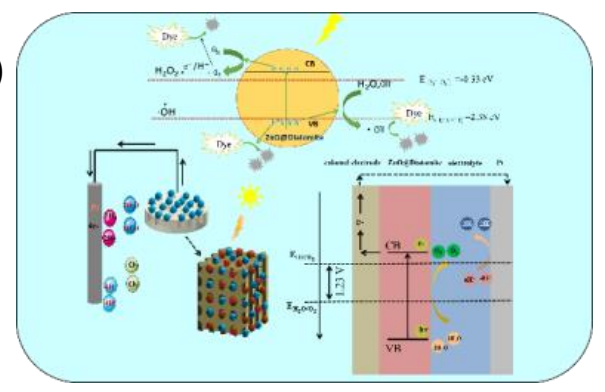

Figure 13. (a) Amperometric I-t curves. (b) Photocurrent density. (c) Nyquist plots of pure ZnO and X\%ZnO@diatomite. (d) Water splitting efficiency of pure $\mathrm{ZnO}$ and $\mathrm{X} \% \mathrm{ZnO@diatomite.} \mathrm{(e,f)} \mathrm{Schematic} \mathrm{representation} \mathrm{of} \mathrm{the} \mathrm{possible} \mathrm{mechanism}$ of photogenerated charge separation at the interface of $\mathrm{X} \% \mathrm{ZnO@diatomite} \mathrm{with} \mathrm{the} \mathrm{corresponding} \mathrm{energy} \mathrm{band} \mathrm{diagram}$ during PEC water splitting.

Electrochemical impedance spectroscopy (EIS) results are shown in Figure 13c for pure $\mathrm{ZnO}$ nanoparticles and $\mathrm{ZnO@diatomite} \mathrm{composite} \mathrm{electrodes.} \mathrm{The} \mathrm{charge} \mathrm{transfer}$ resistance was analyzed by electrochemical impedance spectroscopy (EIS) recorded for catalysts at $0.1 \mathrm{~V}$. Generally, the charge transfer resistance could be indicated by the semicircle in the intermediate frequency region, the lager the diameter, the lager the charge transfer resistance. Figure 13a shows the current versus time (I-t) curves of pure $\mathrm{ZnO}$ nanoparticles and X\%ZnO@diatomite composites in truncated light with a $+0.8 \mathrm{~V}$ vs. RHE $\geq 400 \mathrm{~s}$, on/ off cycle of $50 \mathrm{~s}$. When the lamp was turned off, both photoanodes displayed a very low dark current of approximately $0.0075 \mathrm{~mA} / \mathrm{cm}^{2}$. Under the light, we observed distinct light response platforms with a large and smooth photoflow, indicating a rapid separation of 
photogenerated electrons. Compared with that of the pure $\mathrm{ZnO}$ nanoparticles, the photoresponse currents of the composites were all higher. This result shows a fast light response and reproduces the same light response within $400 \mathrm{~s}$. Furthermore, the electrode material without degradation was observed from the transparent electrolyte solution, suggesting that there may be no change in any structure or morphology in the electrode. Thus, these observations indicate the stability of the photoanode in the PEC process. The obtained fast light response and chemical stability can be attributed to the loading of $\mathrm{ZnO}$, generating $\mathrm{Zn}-\mathrm{O}-\mathrm{Si}$ bonds, which allows photogenerated electrons to separate quickly and efficiently. Figure 13d shows the efficiency diagrams of composites with various loading ratios for photoelectrochemical decomposition of water, where it is clear that the efficiency of the catalyst after loading is greater than that of pure $\mathrm{ZnO}$ nanoparticles, indicating that the $\mathrm{Si}-\mathrm{O}-\mathrm{Zn}$ bonds are conducive to the transmission of electrons and improve the efficiency of photoelectrochemical decomposition of water [31].

To summarize, a schematic of the $\mathrm{X} \% \mathrm{ZnO@diatomite} \mathrm{composite} \mathrm{photoelectrochemical}$ decomposition of water device is shown in Figure 13e, and the interface charge separation process and its energy band diagram are shown in Figure 13f. When the photoelectrode is illuminated, the photogenerated electrons and holes separate as a result of the electric field. The photogenerated electron of $\mathrm{X} \% \mathrm{ZnO} @$ diatomite under light conditions move to the $\mathrm{Pt}$ electrode via an external circuit. These photogenerated electrons reduce water to hydrogen by reaction with hydrogen ions in the electrolyte. Meanwhile, the holes produced in the valence band will effectively transfer to the electrode surface through the valence band because of the action of the built-in electric field, where they participate in the oxidation of water. Thus, an enhanced photocurrent is observed with the X\%ZnO@diatomite composite. The presence of the $\mathrm{X} \% \mathrm{ZnO@diatomite} \mathrm{composite} \mathrm{improves} \mathrm{the} \mathrm{charge} \mathrm{separation}$ efficiency.

\section{Experimental Section}

\subsection{Chemicals and Materials}

Diatomite (Macklin, Shanghai, China), zinc acetate hexahydrate $\mathrm{Zn}\left(\mathrm{OOCCH}_{3}\right)_{2} \cdot 2 \mathrm{H}_{2} \mathrm{O}$ (Alfa Aesar, Shanghai, China), ammonia water (analytical reagent, Beijing, China), acetylacetone (analytical reagent, Tianjin, China), acetone (analytical reagent, Beijing, China), benzene(Aladdin, shanghai, China), TEOA (analytical reagent, Beijing, China), IPA (analytical reagent, Beijing, China), Nafion(Aladdin, shanghai, China), VC (Aladdin, shanghai, China), anhydrous ethanol (analytical reagent, Beijing, China) and deionized water were used for the synthesis of $\mathrm{ZnO}$ and $\mathrm{ZnO} /$ diatomite. During the process of synthesizing $\mathrm{ZnO} /$ diatomite, the molar ratio of $\mathrm{ZnO}$ to diatomite was controlled to synthesize composites with various load proportions. All the reagents listed were used as purchased and without further treatment.

\subsection{Catalyst Preparation}

First, a set mass of diatomite was weighed and placed in a 250-mL round-bottom flask; then, $40 \mathrm{~mL}$ of deionized water was added, and the mixture was stirred with the magnetic force for $30 \mathrm{~min}$ in an ice water bath. Second, $\mathrm{Zn}\left(\mathrm{OOCCH}_{3}\right)_{2} \cdot 2 \mathrm{H}_{2} \mathrm{O}$ was added and stirred for $30 \mathrm{~min}$. Third, while stirring in an ice-water bath, $0.3 \%$ ammonia solution was added drop by drop into a three-neck flask, with a dropping speed of one drop per second. Then $2 \mathrm{~mL}$ of acetylacetone was added $10 \mathrm{~min}$ after the ammonia; when the $\mathrm{pH}$ value of the solution was 10.00, the dropping of the ammonia solution was stopped. This solution was heated in a water bath at $75^{\circ} \mathrm{C}$ for $7 \mathrm{~h}$. Finally, when the reaction was finished, the reacted mixed liquid in the round-bottom flask was washed with deionized water for 3-5 times, washed to neutrality, and naturally dried for $5-15 \mathrm{~h}$. Composites with various proportions of $\mathrm{ZnO}$ and diatomite were prepared by the same method, with loading ratios of $4 \%, 6 \%$, $8 \%, 10 \%$, and $12 \%$. The pure $\mathrm{ZnO}$ was prepared according to the above procedure, except with the addition of diatomite steps. The preparation process is shown in Scheme 2. 


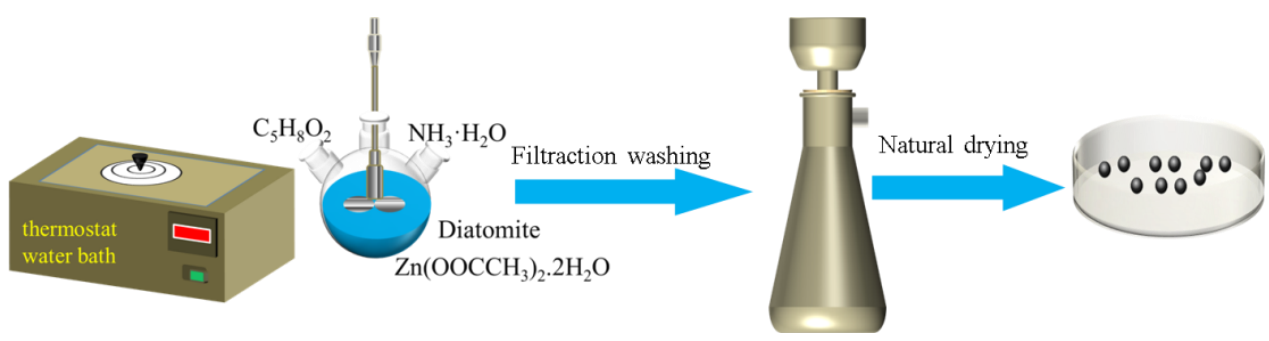

Scheme 2. Flow chart of photocatalyst preparation.

\subsection{Characterization}

\subsubsection{Material Characterization}

The surface morphology of samples was observed using SEM (JSM-7800F and S-4700, Japan) with EDS. The crystallinity of the prepared samples was characterized by XRD recorded using $\mathrm{Cu} \mathrm{K} \alpha$ radiation at a scan rate of $5^{\circ} / \mathrm{min}$ and HRTEM (ARM-200, Japan). The specific surface area and pore size distribution of the prepared samples were characterized by a BET instrument at $77 \mathrm{~K}$ (Micrometrics ASAP 2020, Georgia, USA). UV-vis absorbance was characterized using a UV-VISNIR spectrophotometer (SolidSpec-3700, Shimadzu, Japan). A photoluminescence spectrometer (FL-7000, Hitachi, Japan) was used out to evaluate the photocatalytic activity. XPS was conducted to analyze the elemental chemical environment. EPR (EMX-500 10/12) was used to detect unpaired electrons contained in atoms or molecules from qualitative and quantitative perspectives and to explore the structural properties of their surroundings. At room temperature, in $0.5 \mathrm{M} \mathrm{Na}_{2} \mathrm{SO}_{4}$ solution, a CHI660E electrochemical analyzer was used with a traditional three-electrode system. The prepared $\mathrm{X} \% \mathrm{ZnO@diatomite} \mathrm{catalysts} \mathrm{were} \mathrm{used} \mathrm{as} \mathrm{the} \mathrm{working} \mathrm{electrode,} \mathrm{a}$ glycerol electrode was the parameter electrode, and the pair electrode was composed of graphite.

\subsubsection{Photocatalytic Activity}

Samples with various loading ratios were evaluated using an MB solution photocatalytic degradation method. The analytical balance weighed $50 \mathrm{mg}$ catalyst with a $30 \mathrm{~mL}$ concentration of $5 \mathrm{mg} / \mathrm{L} \mathrm{MB}$ solution added to a $250 \mathrm{~mL}$ glass bottle, as shown in Scheme 3. The bottle was then placed in a heated xenon lamp box. First, static dark adsorption proceeds for $30 \mathrm{~min}$ in dark conditions, and then take $4 \mathrm{~mL} \mathrm{MB}$ solution from the glass bottle into a sample tube measuring $5 \mathrm{~mL}$ and mark it as serial number 1 . Turn on the xenon light and then take $4 \mathrm{~mL} \mathrm{MB}$ solution from the glass bottle. The xenon lamp will always be illuminated. Then, $4 \mathrm{~mL}$ methylene blue solution is taken out every $30 \mathrm{~min}$ and marked as 3-6. The degradation rate was determined by monitoring the variation in $\mathrm{MB}$ solution concentration over time using an ultraviolet visible spectrophotometer (ShimUV-3600). The catalyst with the highest degradation rate was selected to degrade gaseous organic pollutants, including acetone and benzene. The degradation process was performed in headspace vials with a volume of $500 \mathrm{~mL}$. Under sealed conditions, the saturated gas has the same concentration as the liquid. The specific experimental details are similar to those for the MB solution degradation process, but MB solution was replaced by gas-phase organic pollutants. The details of the experiment are as follows: the catalyst $(0.05 \mathrm{~g})$ was added to a headspace vials bottle, and $1 \mathrm{~mL}$ of the saturated gas pollutant was transferred to the headspace vials using a gas chromatographic syringe of $2.5 \mathrm{~mL}$. A xenon lamp $(30 \mathrm{~W})$ was used as a light source during photocatalytic degradation. The headspace vials were placed in light, and the bottle was directly irradiated. The whole process was performed at room temperature. No heating or stirring was used throughout the degradation. Meanwhile, the gas was detected every $30 \mathrm{~min}$, and the corresponding concentration of organic gas pollutants was determined by gas chromatography-mass spectrometry (GC-MS). 


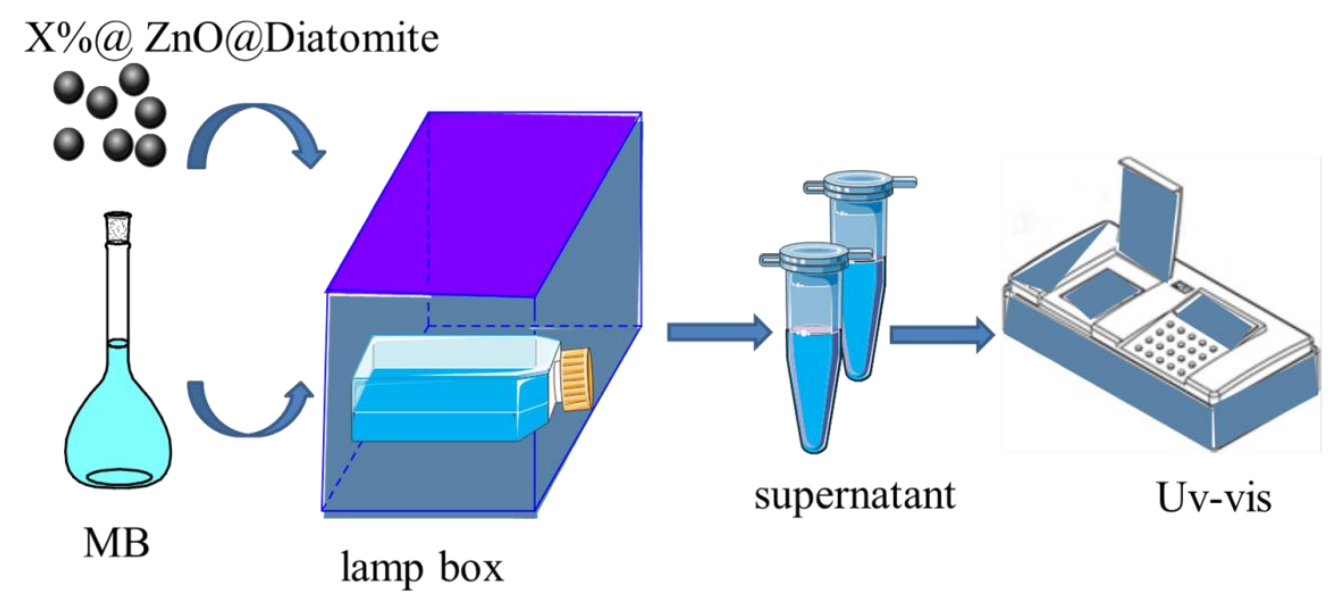

Scheme 3. Flow chart of photocatalyst degradation of MB.

\subsubsection{Electrochemical Measurements of Electrocatalysts}

Photoelectrochemical decomposition of water activity testing of the catalysts used a three-electrode system, including a working electrode, calomel electrode as the reference electrode, and graphite is the counter. The $0.5 \mathrm{M} \mathrm{Na}_{2} \mathrm{SO}_{4}$ solution acted as an electrolyte solution, and the working electrode was prepared without any conductive substance. A total of $10 \mathrm{mg}$ of catalyst was ultrasonically dispersed into a mixed solution of deionized water $(475 \mu \mathrm{L})$, aqueous ethanol $(475 \mu \mathrm{L})$ and Nafion solution $(30 \mu \mathrm{L})$, where the pipettor took $5-\mu \mathrm{L}$ droplets to the platinum carbon electrode as the working electrode, and the platinum carbon electrode area was $0.1256 \mathrm{~cm}^{2}$. All electrodes were connected to an external circuit via a small crocodile needle. It was also ensured that there was no contact between the crocodile needle and the electrolyte. The photocurrent was measured under the irradiation of $150-\mathrm{mW} / \mathrm{cm}^{2}$ xenon lamps. Linear scanning voltammetry (LSV) was performed at a rate of $10 \mathrm{mV} / \mathrm{s}$ between 0.4 and $1 \mathrm{~V}$. Photochemical measurements were performed in both dark and simulated sunlight conditions. The efficiency of the decomposition of water was calculated using the following formula:

$$
\eta(\%)=J\left(1.23-E_{R H E}\right) / I_{\text {light }}
$$

where $\eta(\%)$ is the efficiency of the photoelectrochemical decomposition of water, $E_{R H E}$ is the potential calibrated against RHE and $\mathrm{I}_{\text {light }}$ is photocurrent density.

\section{Conclusions}

X\%ZnO@diatomite were successfully prepared by the precipitation method, and the diameter of the synthesized catalysts was $15-20 \mathrm{~nm}$. The $\mathrm{ZnO}$ has nanoscale features and was relatively uniformly loaded on diatomite, solving the problem of limited utilization and recovery difficulty of nanomaterials. The catalysts were successfully prepared by the green pollution-free precipitation method. Under visible light irradiation, the optimal catalyst showed excellent photocatalytic performance for MB solution, gaseous acetone, and gaseous benzene. The experiments demonstrate that the catalysts have great potential for application to volatile organic compounds. By adjusting the loading ratio, the composite achieved high catalytic degradation, and the best degradation efficiency occurred at a molar loading ratio of $10 \%$. At $+0.8 \mathrm{~V}$ vs. RHE, the maximum hydrocracking efficiency of the $10 \%$ $\mathrm{ZnO} @$ diatomite composite was $0.045 \%$. XPS results proved the existence of $\mathrm{Si}-\mathrm{O}-\mathrm{Zn}$ bonds, providing a theoretical basis for the degradation mechanism. The results are consistent with conclusions obtained from characterization techniques such as XRD and UV-vis and the Photoluminescence (PL) spectra. The experimental catalysts not only can be conveniently recycled, but it also have great potential for the photocatalytic degradation of pollutants. 
Author Contributions: Conceptualization, B.Y. and J.Y.; methodology, B.Y.; software, B.Y., X.L. and Q.W.; validation, B.Y., X.L. and Z.M.; formal analysis, B.Y.; investigation, B.Y.; resources, B.Y.; data curation, B.Y.; writing — original draft preparation, B.Y.; writing-review and editing, B.Y. and J.Y.; visualization, B.Y., J.Y. and X.L.; supervision, J.Y.; project administration, J.Y.; funding acquisition, J.Y. All authors have read and agreed to the published version of the manuscript.

Funding: This research received no external funding.

Data Availability Statement: The raw data supporting the conclusions of this article will be made available by the authors, without undue reservation.

Conflicts of Interest: The authors declare no conflict of interest.

\section{References}

1. Zhang, R.; Fei, C.; Li, B.; Fu, H.; Tian, J.; Cao, G. Continuous size tuning of monodispersed ZnO nanoparticles and its size effect on the performance of perovskite solar cells. ACS Appl. Mater. Interfaces 2017, 9, 9785-9794. [CrossRef] [PubMed]

2. Wang, D.; Zhou, Z.-H.; Yang, H.; Shen, K.-B.; Huang, Y.; Shen, S. Preparation of $\mathrm{TiO}_{2}$ loaded with crystalline nano Ag by a one-step low-temperature hydrothermal method. J. Mater. Chem. 2012, 22, 16306-16311. [CrossRef]

3. Sakthivel, S.; Neppolian, B.; Shankar, M.; Arabindoo, B.; Palanichamy, M.; Murugesan, V. Solar photocatalytic degradation of azo

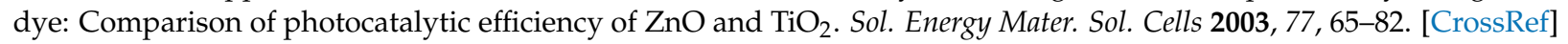

4. Kim, D.; Yong, K. Boron doping induced charge transfer switching of a $\mathrm{C}_{3} \mathrm{~N}_{4} / \mathrm{ZnO}$ photocatalyst from Z-scheme to type II to enhance photocatalytic hydrogen production. Appl. Catal. B Environ. 2021, 282, 119538. [CrossRef]

5. Chankhanittha, T.; Nanan, S. Visible-light-driven photocatalytic degradation of ofloxacin (OFL) antibiotic and Rhodamine B (RhB) dye by solvothermally grown $\mathrm{ZnO} / \mathrm{Bi}_{2} \mathrm{MoO}_{6}$ heterojunction. J. Colloid Interface Sci. 2020, 582, 412-427. [CrossRef] [PubMed]

6. Gupta, N.K.; Bae, J.; Kim, S.; Kim, K.S. Fabrication of Zn-MOF/ZnO nanocomposites for room temperature H2S removal: Adsorption, regeneration, and mechanism. Chemosphere 2021, 274, 129789. [CrossRef] [PubMed]

7. Qian, C.; Yin, J.; Zhao, J.; Li, X.; Wang, S.; Bai, Z.; Jiao, T. Facile preparation and highly efficient photodegradation performances of self-assembled Artemia eggshell-ZnO nanocomposites for wastewater treatment. Colloids Surf. A Physicochem. Eng. Aspects 2021, 610, 125752. [CrossRef]

8. Fernando, J.F.S.; Shortell, M.P.; Noble, C.J.; Harmer, J.R.; Jaatinen, E.A.; Waclawik, E.R. Controlling Au photodeposition on large ZnO nanoparticles. ACS Appl. Mater. Interfaces 2016, 8, 14271-14283. [CrossRef]

9. Hong, R.; Pan, T.; Qian, J.; Li, H. Synthesis and surface modification of ZnO nanoparticles. Chem. Eng. J. 2006, 119, 71-81. [CrossRef]

10. Sernelius, B.; Berggren, K.-F.; Jin, Z.-C.; Hamberg, I.; Granqvist, C.G. Band-gap tailoring of ZnO by means of heavy Al doping. Phys. Rev. B 1988, 37, 10244-10248. [CrossRef] [PubMed]

11. Deng, H.; Fei, X.; Yang, Y.; Fan, J.; Yu, J.; Cheng, B.; Zhang, L. S-scheme heterojunction based on p-type $\mathrm{ZnMn}_{2} \mathrm{O}_{4}$ and n-type $\mathrm{ZnO}$ with improved photocatalytic $\mathrm{CO}_{2}$ reduction activity. Chem. Eng. J. 2021, 409, 127377. [CrossRef]

12. Klingshirn, C. ZnO: Material, physics and applications. ChemPhysChem 2007, 8, 782-803. [CrossRef] [PubMed]

13. Chen, D.; Wang, Z.; Ren, T.; Ding, H.; Yao, W.; Zong, R.; Zhu, Y. Influence of Defects on the photocatalytic activity of ZnO. J. Phys. Chem. C 2014, 118, 15300-15307. [CrossRef]

14. Li, Q.; Zhai, G.; Xu, Y.; Odoom-Wubah, T.; Jia, L.; Huang, J.; Sun, D.; Li, Q. Diatomite supported Pt nanoparticles as efficient catalyst for benzene removal. Ind. Eng. Chem. Res. 2019, 58, 14008-14015. [CrossRef]

15. Pookmanee, P.; Thippraphan, P.; Jansanthea, P.; Phanichphant, S. Characterization and adsorption efficiency of the natural and the modified diatomite via the low temperature hydrothermal route. Adv. Mater. Res. 2012, 506, 425-428. [CrossRef]

16. Chen, C.; Liu, P.; Lu, C. Synthesis and characterization of nano-sized ZnO powders by direct precipitation method. Chem. Eng. J. 2008, 144, 509-513. [CrossRef]

17. Long, X.; Wang, C.; Wei, S.; Wang, T.; Jin, J.; Ma, J. Layered double hydroxide onto perovskite oxide-decorated ZnO nanorods for modulation of carrier transfer behavior in photoelectrochemical water oxidation. ACS Appl. Mater. Interfaces 2020, 12, 2452-2459. [CrossRef]

18. Ristic, M.; Music, S.; Ivanda, M.; Popović, S. Sol-gel synthesis and characterization of nanocrystalline ZnO powders. J. Alloy. Compd. 2005, 397, L1-L4. [CrossRef]

19. Aksoy, S.; Caglar, Y.; Ilican, S.; Caglar, M. Sol-gel derived Li-Mg co-doped ZnO films: Preparation and characterization via XRD, XPS, FESEM. J. Alloys Compd. 2012, 512, 171-178. [CrossRef]

20. Kaftelen, H.; Ocakoglu, K.; Thomann, R.; Tu, S.; Weber, S.; Erdem, E. EPR and photoluminescence spectroscopy studies on the defect structure of ZnO nanocrystals. Phys. Rev. B 2012, 86, 014113. [CrossRef]

21. Kappers, L.; Gilliam, O.; Evans, S.; Halliburton, L.; Giles, N. EPR and optical study of oxygen and zinc vacancies in elec-tronirradiated ZnO. Nucl. Instrum. Methods Phys. Res. Sect. B Beam Interact. Mater. Atoms. 2008, 266, 2953-2957. [CrossRef]

22. Al-Gaashani, R.; Radiman, S.; Daud, A.; Tabet, N.; Al-Douri, Y. XPS and optical studies of different morphologies of ZnO nanostructures prepared by microwave methods. Ceram. Int. 2013, 39, 2283-2292. [CrossRef] 
23. Abdel-Wahab, M.S.; Jilani, A.; Yahia, I.; Al-Ghamdi, A.A. Enhanced the photocatalytic activity of Ni-doped ZnO thin films: Morphological, optical and XPS analysis. Superlattices Microstruct. 2016, 94, 108-118. [CrossRef]

24. Wu, L.; Zhou, Y.; Nie, W.; Song, L.; Chen, P. Synthesis of highly monodispersed teardrop-shaped core-shell. $\mathrm{SiO}_{2} / \mathrm{TiO}_{2}$ nanoparticles and their photocatalytic activities. Appl. Surf. Sci. 2015, 351, 320-326. [CrossRef]

25. Yu, X.; Zhao, Z.; Zhang, J.; Guo, W.; Li, L.; Liu, H.; Wang, Z.L. One-step synthesis of ultrathin nanobelts-assembled urchin-like anatase $\mathrm{TiO}_{2}$ nanostructures for highly efficient photocatalysis. CrystEngComm 2017, 19, 129-136. [CrossRef]

26. Xu, H.-Q.; Hu, J.; Wang, D.; Li, Z.; Zhang, Q.; Luo, Y.; Yu, S.-H.; Jiang, H.-L. Visible-light photoreduction of $\mathrm{CO}_{2}$ in a metal-organic framework: Boosting electron-hole separation via electron trap states. J. Am. Chem. Soc. 2015, 137, 13440-13443. [CrossRef]

27. Kang, Y.; Yang, Y.; Yin, L.-C.; Kang, X.; Wang, L.; Liu, G.; Cheng, H.-M. Selective breaking of hydrogen bonds of layered carbon nitride for visible light photocatalysis. Adv. Mater. 2016, 28, 6471-6477. [CrossRef]

28. Azarang, M.; Shuhaimi, A.; Yousefi, R.; Golsheikh, A.M.; Sookhakian, M. Synthesis and characterization of ZnO NPs/reduced graphene oxide nanocomposite prepared in gelatin medium as highly efficient photo-degradation of MB. Ceram. Int. 2014, 40, 10217-10221. [CrossRef]

29. Neena, D.; Kondamareddy, K.K.; Bin, H.; Lu, D.; Kumar, P.; Dwivedi, R.K.; Pelenovich, V.; Zhao, X.-Z.; Gao, W.; Fu, D. Enhanced visible light photodegradation activity of $\mathrm{RhB} / \mathrm{MB}$ from aqueous solution using nanosized novel Fe-Cd co-modified ZnO. Sci. Rep. 2018, 8, 1-12. [CrossRef]

30. Wang, Y.N.; Li, J.; Wang, Q. The performance of daylight photocatalytic activity towards degradation of MB by the flower-like and approximate flower-like complexes of graphene with ZnO and Cerium doped ZnO. Optik 2020, 204, 164131. [CrossRef]

31. Jeong, K.; Deshmukh, P.R.; Park, J.; Sohn, Y.; Shin, W.G. ZnO-TiO ${ }_{2}$ core-shell nanowires: A sustainable photoanode for enhanced photoelectrochemical water splitting. ACS Sustain. Chem. Eng. 2018, 6, 6518-6526. [CrossRef] 